University of South Florida

DIGITAL COMMONS

Digital Commons @ University of

@ UNIVERSITY OF SOUTH FLORIDA

South Florida

School of Geosciences Faculty and Staff

Publications

School of Geosciences

$5-2020$

\title{
Resolution of Lava Tubes With Ground Penetrating Radar: The TubeX Project
}

\author{
Sanaz Esmaeili \\ University of South Florida, esmaeili@mail.usf.edu \\ Sarah Kruse \\ University of South Florida, skruse@usf.edu \\ Sajad Jazayeri \\ University of South Florida, sjazayeri@mail.usf.edu \\ P. Whelley \\ University of Maryland \\ E. Bell \\ University of Maryland
}

See next page for additional authors

Follow this and additional works at: https://digitalcommons.usf.edu/geo_facpub

Part of the Earth Sciences Commons

\section{Scholar Commons Citation}

Esmaeili, Sanaz; Kruse, Sarah; Jazayeri, Sajad; Whelley, P.; Bell, E.; Richardson, J.; Garry, W. B.; and Young, K., "Resolution of Lava Tubes With Ground Penetrating Radar: The TubeX Project" (2020). School of Geosciences Faculty and Staff Publications. 2235.

https://digitalcommons.usf.edu/geo_facpub/2235

This Article is brought to you for free and open access by the School of Geosciences at Digital Commons @ University of South Florida. It has been accepted for inclusion in School of Geosciences Faculty and Staff Publications by an authorized administrator of Digital Commons @ University of South Florida. For more information, please contact digitalcommons@usf.edu. 


\section{Authors}

Sanaz Esmaeili, Sarah Kruse, Sajad Jazayeri, P. Whelley, E. Bell, J. Richardson, W. B. Garry, and K. Young 


\section{RESEARCH ARTICLE 10.1029/2019JE006138 \\ Resolution of Lava Tubes With Ground Penetrating Radar: The TubeX Project}

Key Points:

- Ground penetrating radar (GPR) and LiDAR were used to map lava tubes Lava Beds National Monument, CA, USA

- From the GPR data, the lave tube depth and width can be generally well constrained, but the floor position can be difficult to resolve

- Modeling of expected GPR responses on the Moon and Mars suggests this method should be similarly effective for tube mapping in those settings

Correspondence to:

S. Esmaeili,

esmaeili@mail.usf.edu

Citation:

Esmaeili, S., Kruse, S., Jazayeri, S., Whelley, P., Bell, E., Richardson, J., et al. (2020). Resolution of Lava Tubes with ground penetrating radar: The TubeX project. Journal of Geophysical Research: Planets, 125, e2019JE006138. https://doi.org/10.1029/2019JE006138

Received 26 JUL 2019

Accepted 20 FEB 2020

Accepted article online 3 MAR 2020

(C)2020. American Geophysical Union. All Rights Reserved. This article has been contributed to by US Government employees and their work is in the public domain in the USA.

\author{
S. Esmaeili ${ }^{1}$ D, S. Kruse ${ }^{1}$ (D) S. Jazayeri ${ }^{1}$ (D) P. Whelley ${ }^{2,3}$ (D) E. Bell ${ }^{4}$ (D) J. Richardson ${ }^{2,3}$ (D), \\ W. B. Garry' ${ }^{2}$, and K. Young ${ }^{2}$ iD \\ ${ }^{1}$ School of Geosciences, University of South Florida, Tampa, FL, USA, ${ }^{2}$ NASA Goddard Space Flight Center, Greenbelt, \\ MD, USA, ${ }^{3}$ Department of Astronomy, University of Maryland, College Park, MD, USA, ${ }^{4}$ Department of Geology, \\ University of Maryland, College Park, MD, USA
}

Abstract Remote sensing surveys of the Moon and Mars show evidence of lava tubes, which are potential safe havens for human crews and their equipment. Ground penetrating radar (GPR) can be used to map tubes because the void/rock interface at tube ceilings and floors strongly reflects radar pulses. We have tested the capacity of GPR to sense lava tube geometry at Lava Beds National Monument in California, USA. GPR and detailed light detection and ranging (LiDAR) data are presented for two tubes: Skull Cave, with a few meters of overburden, diameter $\sim 10-20 \mathrm{~m}$, and a rubbly floor; and Valentine Cave, with similarly thin overburden, diameter $\sim 1-3 \mathrm{~m}$, and a flatter smoother floor. On both caves GPR clearly resolves the ceiling and permits good estimates of the cave width as validated with LiDAR data. Where GPR fails, the primary cause is inferred to be strong out-of-plane effects due to complex 3-D geometries. Recovery of the floor position requires migrating the GPR data with a 2-D velocity model, as signal velocity is faster in void space. We find that floor position is recoverable in caves whose voids are taller than the radar wavelength ( $\sim 3 \mathrm{~m}$ in this study). Forward modeling assuming planetary parameters suggests that GPR should be similarly successful on the Moon or Mars.

Plain Language Summary Lava tubes are tunnel-like caves found in lava flows on the Earth and other planets such as the Moon and Mars. On other planets, lava tubes can offer potential safe havens for human crews and their equipment, so developing methods for identifying and characterizing them from the surface is important. Geophysical methods are ideal tools for exploring lava tubes, among which ground penetrating radar (GPR), which does not affect rocks in the study area, is fast and relatively simple to use. In this study, we have used GPR and other tools to map lava tubes in Lava Beds National Monument, California (USA). We have collected GPR, GPS, and LiDAR data on two tubes. Their depths and widths are relatively simple to find with GPR, while the height and floor are the most challenging characteristics to be determined. Therefore, special numerical modeling algorithms, migration techniques, are used which require a general knowledge of subsurface geometry. Our tests show that with careful algorithm utilization and a good velocity model, GPR data are likely to provide an acceptable tube model.

\section{Introduction}

Planetary lava tubes and void spaces could provide safe havens for human crews and protect their life support equipment from harmful radiation, fluctuating surface temperatures, and meteorite impacts (Horz, 1985). Analyses of remote sensing surveys, such as orbital radar, gravity data, and orbital photographic, suggest the existence of lava tubes beneath the lunar and Martian surface (e.g., Carr, 1974; Chappaz et al., 2017; Cushing, 2012; Daga et al., 2013; Haruyama et al., 2009; Kaku et al., 2017; Robinson et al., 2012). Before use or occupation of any planetary lava tube, remote characterization of tube geometry will be critical. In particular, ground penetrating radar (GPR) surveys from surface instruments offer higher resolution than orbital data and could be a key tool in lava tube reconnaissance surveys.

Lava tubes are evacuated pathways within lava flows and are common volcanic features on Earth, the Moon, and Mars. Observations of flowing lava (e.g., Calvari \& Pinkerton, 2004; Greeley \& Hyde, 1972) and lava flow models (Keszthelyi, 1995) commonly indicate that tubes enable lava to stay hotter longer and therefore flow farther. Lava tube caves (i.e., preserved and accessible tube segments) provide a window into lava flow interiors (Kauahikaua et al., 1998; Whelley, Garry, Young, et al., 2017) that can illuminate lava flow 


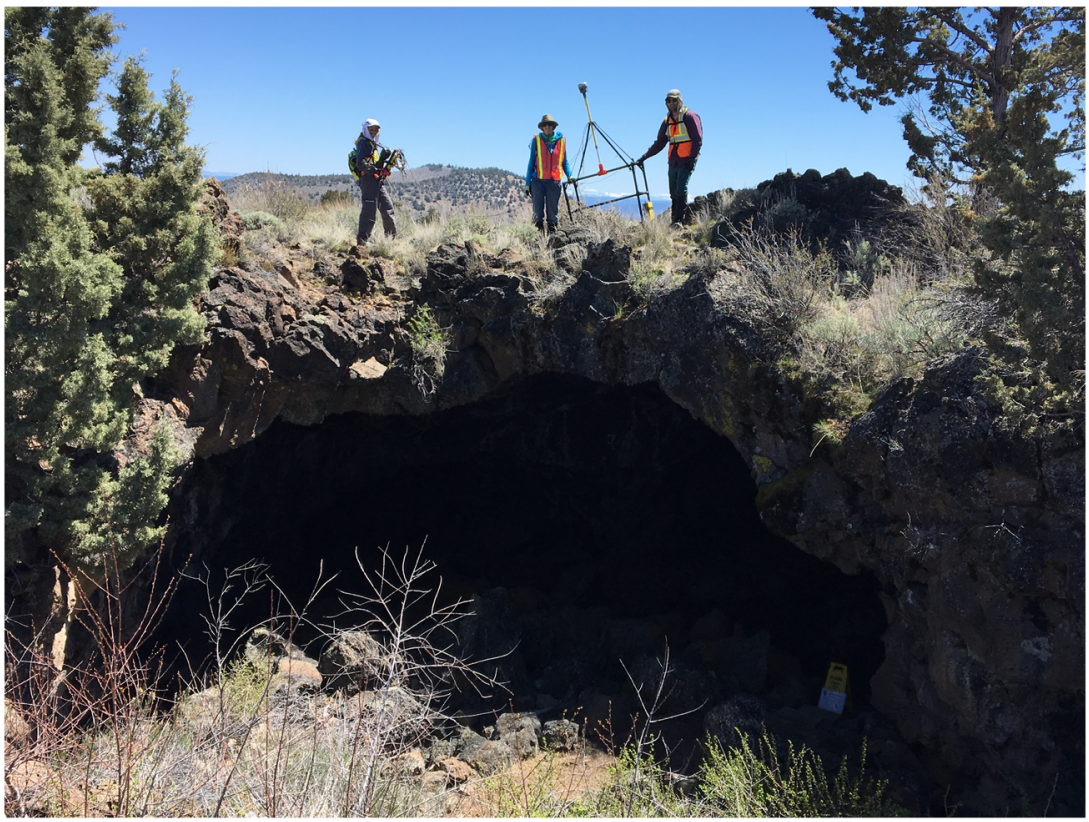

Figure 1. Our survey of Hercules Leg Cave lava tube at LBNM with the 100-MHz GPR transmitting and receiving antennas and an RTK GPS system. Several features pose ubiquitous challenges to obtain quality resolution GPR data of the cave: complex fracturing in the overburden rock, blocks of that have fallen from the ceiling onto the cave floor, roughness in the surface topography, and vegetation that prohibits acquisition of straight-line profiles. Location shown on Figure 3.

dynamics (e.g., temperature, flow rate, cooling rate, and compositional trends), produce environmental niches, host subsurface water (e.g., Northup et al., 2011), and preserve pristine lava samples. Lava tubes form through one of two primary processes: roofing over of lava channels or inflation of sheet flows (Hon et al., 1994; Peterson et al., 1994; Peterson \& Swanson, 1974). In cross section tubes often take on an approximately hemispherical shape, with a flat floor (Figure 1). Diameters can range up to tens of meters on Earth and perhaps a kilometer or more on the Moon (Blair et al., 2017; Chappaz et al., 2017); tube lengths can extend several tens of kilometers.

Geophysical tools are potentially powerful exploratory techniques for recovering lava tube geometries. Meglich et al. (2003) performed a suite of geophysical surveys including magnetics, GPR, high-resolution shear wave reflection, and electrical resistivity at Lava Beds National Monument (LBNM) in northern California, USA, to locate subsurface voids in advance of roadway construction activities. The different methods showed different scales of resolution: For example, they found that GPR could locate the tubes' ceiling only for those are less than $4 \mathrm{~m}$ deep with 200-MHz antennas, while the high-resolution shear wave method was effective at determining depths as well as width estimates over voids with more than $3 \mathrm{~m}$ of overburden, and both magnetic and resistivity tools could detect the presence of voids $>8$-m diameter at depths of 8-9 $\mathrm{m}$. They conclude that it would be most effective to use a combination of geophysical methods to locate lava tubes.

Most other lava tube investigations have focused on the use of GPR, because it offers the promise of most direct resolution of tube geometry (Olhoeft et al., 2000; Miyamoto et al., 2002; Meglich et al., 2003; Miyamoto et al., 2003; Bernold \& Immer, 2004; Miyamoto et al., 2005; Heggy et al., 2006; Khan et al., 2007; Rowell et al., 2010; Conyers, 2013). GPR functions by transmitting an electromagnetic pulse into the ground and then measuring the amplitude and travel time of energy reflected from subsurface anomalies. These anomalies are defined by contrasts in their electrical properties with that of the background media. The most significant electrical properties are the relative permittivity (the ratio of the electrical permittivity to that of free space) and the electrical conductivity. For a thorough description of GPR theory and applications, see Cassidy and Jol (2009) or Daniels (2004).

GPR has been used to locate and characterize lava tubes because the air/rock interface at tube ceilings and floors can strongly reflect radar pulses (Conyers, 2013). While GPR data have been acquired over, inside, around, and through lava tubes, and between lava tubes and the surface, we focus here on surface surveys 

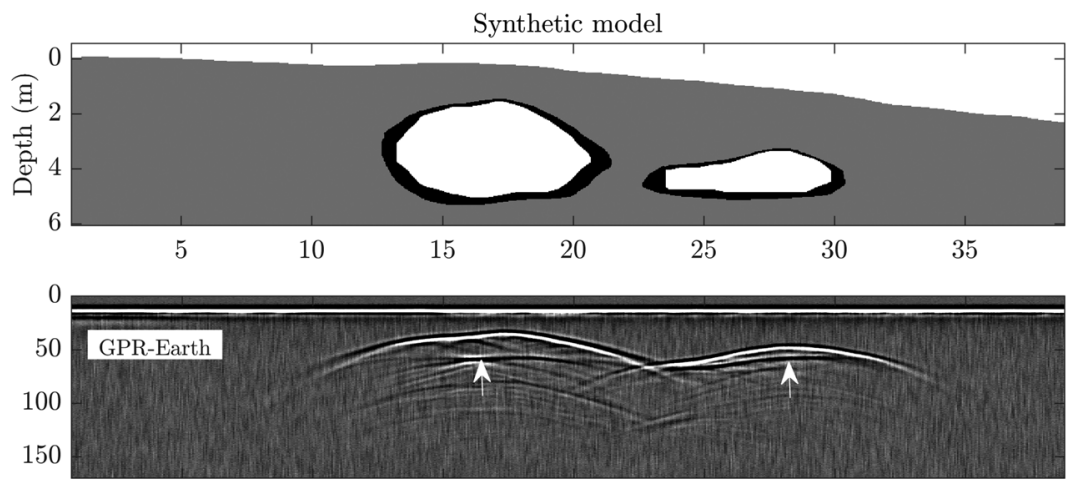

10

15

20

25

30

35
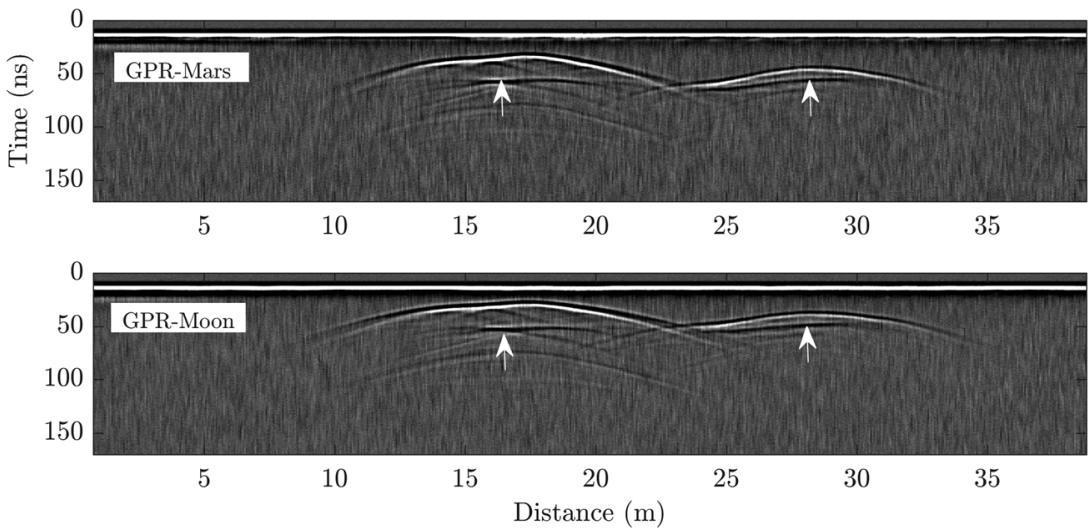

Figure 2. Top: Model of cross section through two branches of a tube, based on geometry measured with LiDAR at GPR profile 29-1 over Valentine Cave in LBNM (location shown on Figures 3 and 4). Bottom: For each GPR profile, permittivity and conductivity parameters are assigned to the gray and black media expected for the environment, as listed in Table 1. White = void. Synthetic GPR profiles (generated by GPRMax, Giannopoulos, 2005) for an ungained $100-\mathrm{MHz}$ crossing are computed for representative values estimated for Earth, Mars, and the Moon. Noise is added to the synthetic data with a Gaussian distribution of high-frequency noise centered at $200 \mathrm{MHz}$ and peak value of $15 \%$ of the pulse amplitude, and lower-frequency noise ( $50 \mathrm{MHz}$ ) added at a lower level (15\% of pulse amplitude). White arrows show reflections coming from cave floor.

aimed at detecting and resolving the dimensions and positions of underlying lava tube caves, as might be done in lunar or Martian exploration. Figure 2 shows an example of synthetic GPR profiles (generated by GPRMax, Giannopoulos, 2005) expected over adjacent branches of a measured lava tube in LBNM. Previous studies have mainly focused on detection of the tubes, primarily through detection of a strong GPR reflection from the tube ceiling (e.g., Conyers, 2013; Meglich et al., 2003; Miyamoto et al., 2005; Rowell et al., 2010).

Resolution of tube dimensions is more challenging than ceiling detection. As illustrated in Figure 2, the raw GPR profile is a filtered and distorted view of the subsurface. The floor arrival time appears "pulled up" relative to the ceiling arrival because the wave travels faster in the void than in surrounding rock. Heggy et al. (2006) found similar effects with resolving a lava tube cave floor on a tube-parallel profile for a void with floor at 3- to 9-m depth beneath a ceiling 1-4 m below ground surface. However, they do not try to accurately recover cave thickness by considering variations in radar wave velocities where tube dimensions change. Rowell et al. (2010) and Conyers (2013) describe the distortions of floor returns expected for a hemispherical tunnel and show their presence in GPR data over lava tubes.

Tube width is also distorted in GPR profiles. Energy reflected off the sloped ceilings is picked up by the GPR when it is off to the side (not directly above) the tube; this energy thus plots in the radar profile as the "wings" that extend laterally beyond the true tube width (Figure 2). Smooth tunnel walls are invisible to the GPR receiver wherever they are too steep to reflect energy back up to the surface. However, 
irregularities in the structure of walls, such as fractures or benches, will diffract energy, producing upside-down " $U$ " s characteristic of point-like anomalies that scatter wave energy.

Techniques for undoing the distortions inherent in reflection profiles in media with variable velocities are referred to as migration. Migration methods have been critical to oil exploration and are widely described in reflection seismic literature (e.g., Yilmaz, 1987). Rowell et al. (2010) illustrate the sharpening of a ceiling reflection with migration and thereby recover a better measure of the width of a lava tube, but they don't illustrate recovery of floor geometry via migration. However, knowledge of tube geometry will be critical when considering tubes as potential habitation resources (Sauro et al., 2018). Ultimately, a combination of GPR, other high-resolution geophysical methods, and innovative robotic systems may be essential in initial exploration and characterization of planetary lava tubes (Daga et al., 2013).

This paper describes the resolution limits of GPR for characterizing lava tubes from a planetary surface, with a focus on selected terrestrial analog data collected over two distinctive lava tubes in LBNM. Each aspect of tube resolution presents its own challenges, including challenges in resolving geometry; detection of tube location (ceiling) and overburden thickness; resolution of tube width; detection and resolution of floor (and therefore tube height); and detection of pillars and branching within tubes.

This work was conducted as part of the TubeX project (Esmaeili et al., 2017; Whelley, Garry, Young, et al., 2017; Bell et al., 2018; Esmaeili et al., 2018a; Esmaeili et al., 2018b; Young, Whelley, Kruse, Esmaeili, Jazayeri, Bell, et al., 2018; Young, Whelley, Kruse, Esmaeili, Jazayeri, Garry, et al., 2018). TubeX aims to develop an exploration and characterization strategy for lava tubes using a combination of field portable instruments and geophysical techniques including GPR, seismic, magnetic, gravity, and handheld X-ray fluorescence spectroscopy. In TubeX surveys at LBNM, these methods are all calibrated against lava tube cave geometries and overlying surface topography measured directly with light detection and ranging (LiDAR) scanning. The LiDAR data are further used to create synthetic geometry models of caves to simulate expected GPR instrument responses on Earth, the Moon, and Mars (as in Figure 2).

\section{Study Site}

LBNM is located in northern California, on the northern flank of Medicine Lake shield volcano in the Cascade Range (Figure 3). LBNM contains numerous cinder cones and volcanic flows (Donnelly-Nolan \& Champion, 1987) as well as hundreds of lava tubes of varying size, shape, and geometry (Larson \& Larson, 1990). Mapped lava tubes and segments at the Monument range in length from tens of meters to kilometers, with overburden thickness from $<1 \mathrm{~m}$ to a few tens of meters, and with cave floor depths to $45 \mathrm{~m}$ below land surface (Larson \& Larson, 1990). Tubes vary in complexity, as illustrated in Figures 4-6. This range of complexity is particularly well suited to this project as tube geometries present below other planetary surfaces are unknown, and this tube diversity enables us to test the ability of GPR to image tubes of different sizes and geometries.

TubeX data collection at LBNM took place in two phases in April-May 2017 and September 2018. In total, the two campaigns acquired $\sim 8.4 \mathrm{~km}$ of GPR data over Valentine, Skull, Hercules Leg, Indian Well, Natural Bridge, Incline, and Ship \& Dinghy caves. In this paper, we focus on selected lines crossing over Skull and Valentine caves (Figures 4-6). Preliminary results from other caves are consistent with our findings on Valentine and Skull caves. These caves are complementary in age, size, and floor texture, as described below.

\subsection{Skull Cave}

Skull Cave (entrance, $41.7314^{\circ} \mathrm{N}, 121.5107^{\circ} \mathrm{W}$ ) is a multilevel segment of a $36 \pm 16 \mathrm{ka} 16-\mathrm{km}$-long lava tube system that originates from Modoc crater (geologic unit bmc in Donnelly-Nolan \& Champion, 1987; Donnelly-Nolan, 2010) (Figures 4 top and 5). There are two principal levels in Skull Cave (Waters et al., 1990) (Figure 5). The cave entrance is the western end of the larger, upper level. This opening is on the eastern end of a collapse trench about $137 \mathrm{~m}$ long. The entrance offers a three-dimensional view of a blocky surface flow, one of the largest in LBNM. Skull Cave's lower level, accessed by a pit connecting the levels, extends westward beneath the upper level. Several rooms on the lower level are floored by ice (Waters et al., 1990). The earliest record of a visit to Skull Cave was in 1892, by E. L. Hopkins, and this cave was named by him after a large accumulation of bones, including those of two humans, found at the bottom of the pit (Larson \& Larson, 1990). 


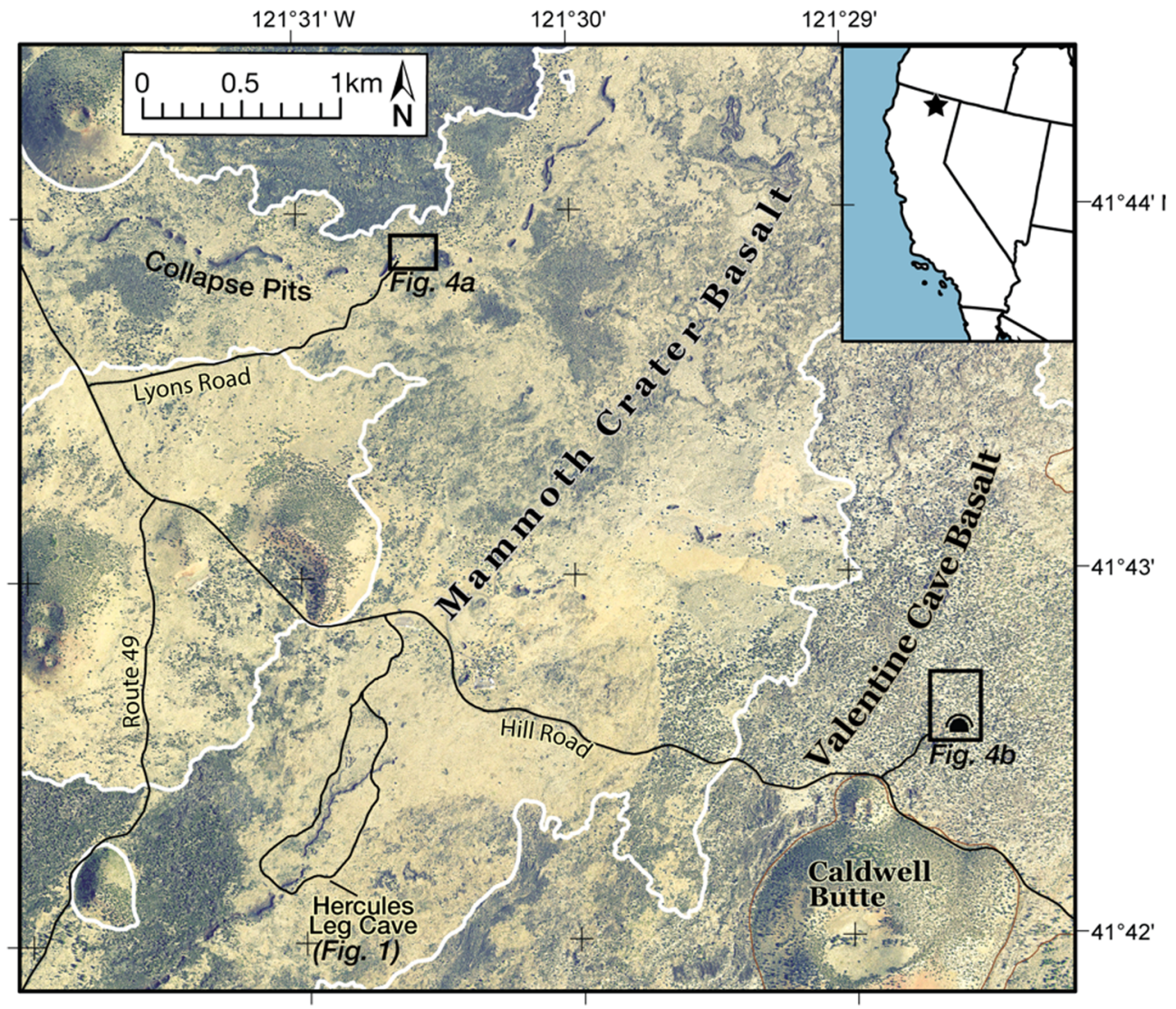

Figure 3. Study area within Lava Beds National Monument (California, USA). Pit chains are visible in this orthoimage basemap (basemap is National Agricultural Image Program Orthomosaic) where lava tubes have collapsed. Tube systems in this study are formed within basalt flows (boundaries drawn in white, Ramsey et al., 2010) whose sources are off-map to the southwest. Focused caves in this work include Skull Cave (Figure 4 top) and Valentine Cave (Figure 4 bottom).

\subsection{Valentine Cave}

Valentine Cave (entrance, $41.7088^{\circ} \mathrm{N}, 121.4784^{\circ} \mathrm{W}$, Figure 4 bottom) has an estimated age of 11 ka and is younger than most other caves in the monument and originates from the Tickner Chimneys vents (geologic unit $b v c$ in Donnelly-Nolan \& Champion, 1987; Donnelly-Nolan, 2010). The roof is thin (< 5 m), allowing tree roots to penetrate into the cave at several places. The entrance is surrounded by blocks from the collapsed surface with the floor composed of ropy lava (pāhoehoe) (Waters et al., 1990). Larson and Larson (1990) describe the ceiling entrance of Valentine Cave to be made of dark patches of lava stalactites that are separated by white bands of water-deposited minerals (Figure 7 left). Pillars are observed at the entrance (6 m wide, $18 \mathrm{~m}$ long) (Figure 7, left) and $\sim 36 \mathrm{~m}$ downstream into the tube (Waters et al., 1990).

\section{Materials and Methods}

In this study, we integrate GPR and LiDAR to investigate strategies for lava tube exploration and imaging. These techniques have been separately deployed on Earth in a variety of geologic contexts with great success. To date and to the best of our knowledge, they have not been combined before to study lava tubes or to develop human exploration strategies for the examination of another planetary surface (Young, Whelley, Kruse, Esmaeili, Jazayeri, Bell, et al., 2018).

\subsection{GPR}

We used a PulseEKKO 100 GPR system from Sensors and Software with 100-MHz unshielded antennas in both data collection phases, with an Ultra receiver in the 2018 campaign. The Ultra receiver is capable of faster stacking of GPR traces, which decreases the random noise floor and increases the imaging depth 

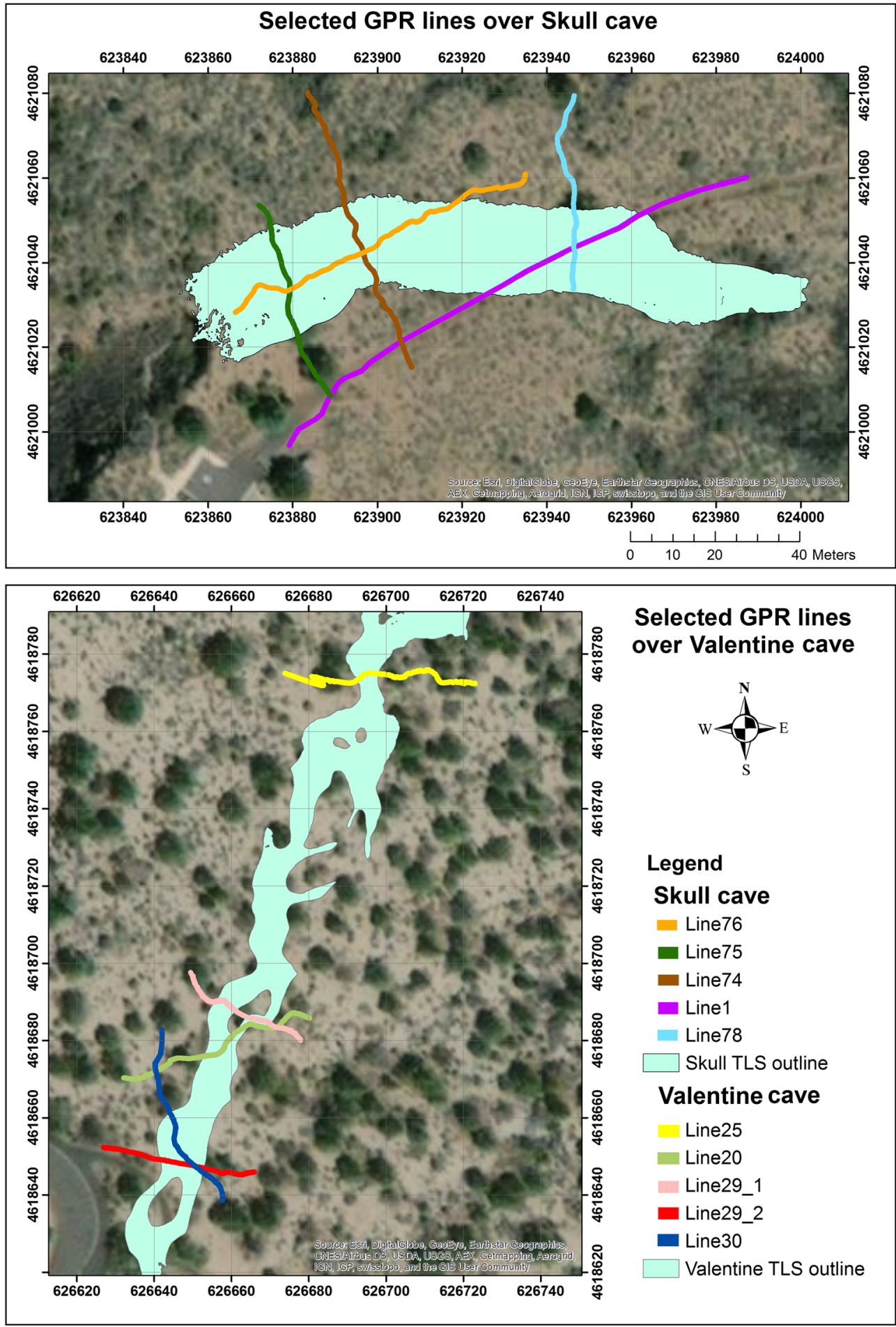

Figure 4. Maps of GPR and LiDAR surveys of two lava tubes at LBNM: (top) Skull Cave; (bottom) Valentine Cave. Selected GPR survey lines are mapped over each cave. Green polygons represent terrestrial LiDAR scan (TLS) coverage of the tubes' interiors. At Skull, small holes in the coverage polygon are TLS coverage gaps; at Valentine, larger holes are pillars within the tube (see Figure 7). Grid coordinates given in UTM zone $10 \mathrm{~N}$.

(https://www.sensoft.ca/blog/ultra-receiver/). For keeping track of GPR trace positioning, we built a simple boom to mount a Trimble R10 RTK (Real-Time Kinematic) GPS on the center of GPR antennas rig above the midpoint between transmitter and receiver antennas but $\sim 1.5 \mathrm{~m}$ above to avoid noise interference (Figure 1). 


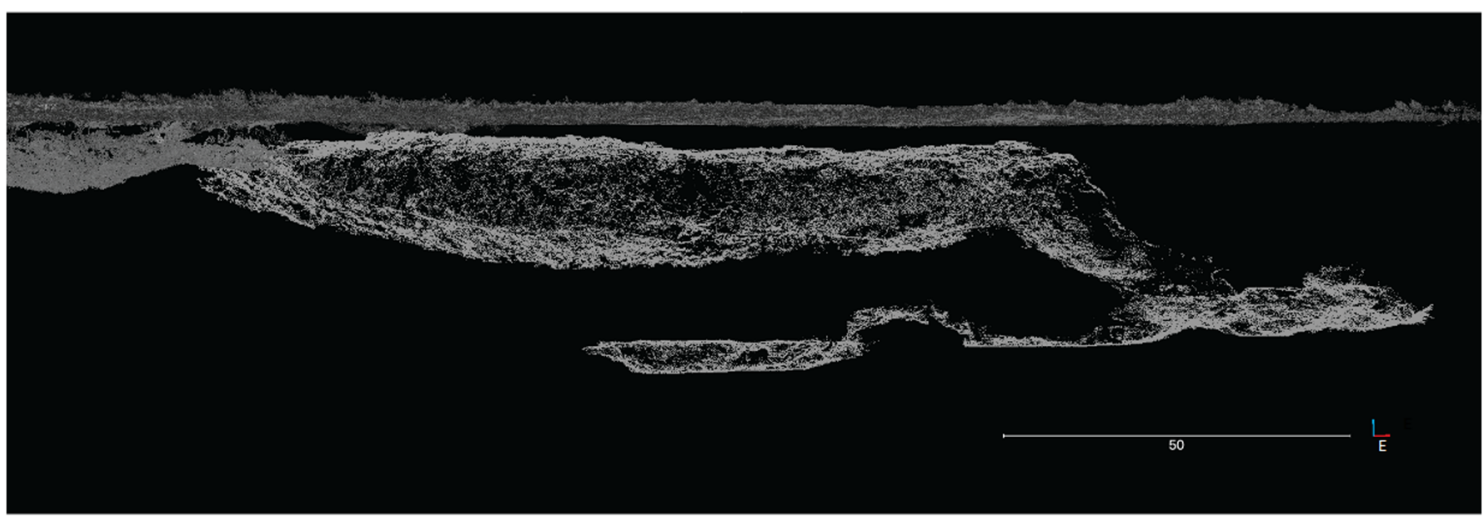

Figure 5. LiDAR data of Skull Cave (LBNM) that shows a side view of the surface and two different mapped levels. Ice forms the flat floor of the deeper level. Entrance is on the left (west) side of the figure. Depth from the surface to floor of the lower level is almost $45 \mathrm{~m}$.

The GPR profiles described here were collected on unpaved roads and mostly on uneven sandy terrain covered with dry bushes. In this terrain we could not collect data along a straight line or use an odometer. Instead, in the off-trail settings we attempted to acquire a trace approximately every $20 \mathrm{~cm}$ and recorded the GPS position each second and merged GPR traces and GPS locations based on time.

A challenge in the field was the loss of real-time kinematic positioning (RTK) for the GPS antenna for some sections of the GPR lines which reduced the positioning accuracy for some traces in some lines. In such cases, we compared GPR-synced GPS locations with ground elevations measured from the LiDAR scans and shifted profile segments by finding the offset that best fit the GPR coordinates to the LiDAR coordinates (typically shifts on the order of a meter). An algorithm was developed, for all of the data, to correct the elevated sensor position down to ground level. GPS data were smoothed with a 5-point running average following by modifications on trace coordinates if it was needed. All above-mentioned modifications were applied using self-generated MATLAB scripts.

Finally, many GPR processing steps assume a uniform trace interval, so traces were interpolated onto a uniform spacing before further data processing. This step and initial GPR processing steps were run using self-generated MATLAB scripts and also the Reflexw software package (Sandmeier, 1998).

In the 2017 field campaign four traces were typically stacked at each location before saving the average. During the 2018 field campaign, much higher data stacking (4096-16384 traces per position) was possible with the Ultra receiver and was used to increase the signal-to-noise ratio.

Following position corrections, GPR data require a few standard processing steps to make data presentable and interpretable. The processing flow used in this study is as follows: dewow filter ( $15 \mathrm{~ns}$; filter variable for each line), time zero correction, band-pass filter ( 20-200 MHz; variable for each line), gain, migration, and topographic corrections (refer to Daniels, 2004, for descriptions of GPR data processing). Dewow, time zero

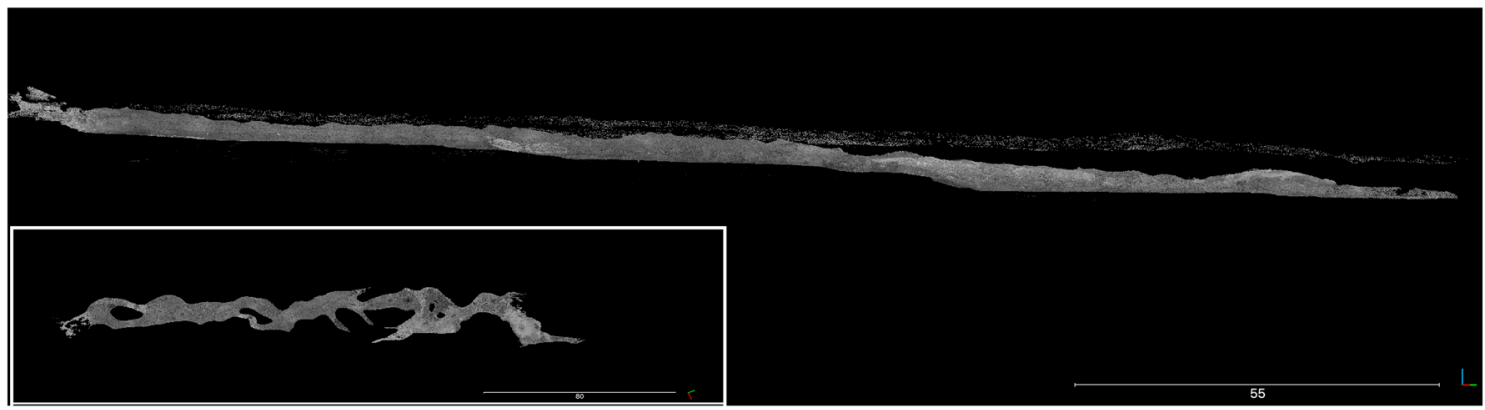

Figure 6. LiDAR data for Valentine Cave (LBNM) that shows a side view of the surface and cave. The entrance is on the left (west) side of the figure. The small bottom box shows the top view, clearly showing the pillars. 


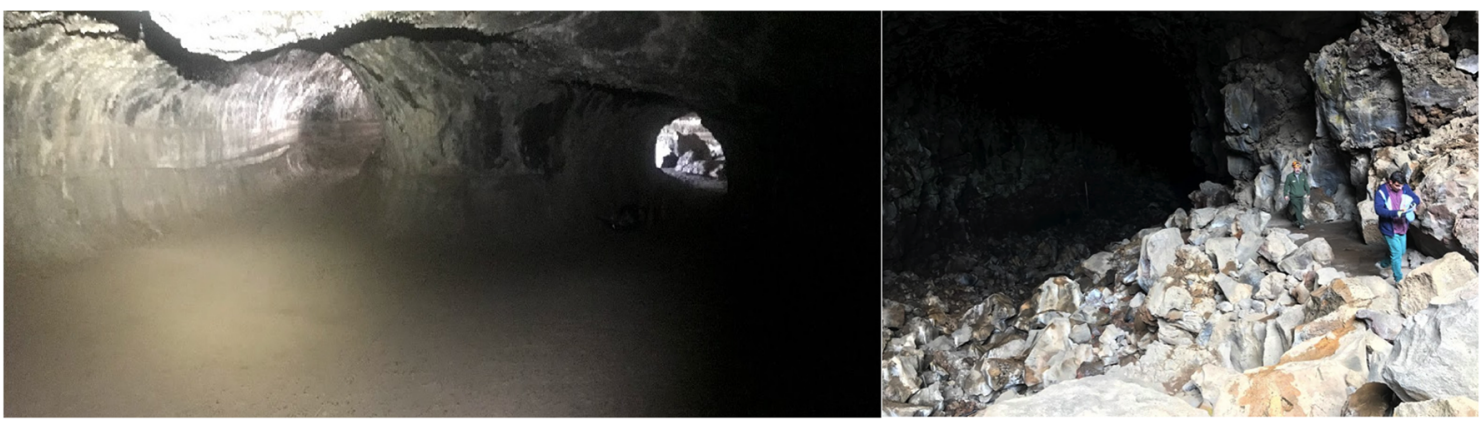

Figure 7. Left: Pillar at the entrance of Valentine Cave and white bands of water-deposited minerals in the walls. Right: The entrance to Skull Cave. Different floor textures are clearly seen in these images (pāhoehoe vs. blocky/rubble).

correction, and band pass are applied in Reflexw software. Gains, if applied, are performed in Reflexw or Seismic Unix (Stockwell, 1999), and migrations are done with Seismic Unix. For migrated lines in this paper, migration was applied to ungained GPR sections, as gain functions change relative amplitudes and phase relationships, which should be preserved for optimal migration results (Cassidy \& Jol, 2009). Topography is corrected after migration using self-generated MATLAB scripts. (Lehmann \& Green, 2000, describe the impacts of the order of migration and topographic correction.)

\subsection{LiDAR}

We used a Riegl VZ-400 LiDAR scanner inside the lava tubes and on the surface above the lava tubes following techniques developed in previous studies (Garry, Hughes, et al., 2016; Garry, Whelley, et al., 2016; Garry et al., 2017; Whelley, Garry, Hamilton, et al., 2017). LiDAR can produce high-resolution point clouds of lava tubes by bouncing light pulses off a surface, detecting their return, and precisely measuring the two-way travel time (Cashman et al., 2013). Using these data sets, we produce three-dimensional $\mathrm{cm}$-resolution representations of each lava tube, which are used to inform models of tube shapes and as a reference for GPR results.

For comparison against GPR data, the point clouds are used to produce surface meshes, in CloudCompare, with horizontal 10-cm spacing in the direction perpendicular and parallel to the main axis of the cave, and then resampled onto $x-y$ positions of the interpolated GPR traces. Computations are done with MATLAB scripts.

\section{Resolution of Lava Tubes From GPR Data}

Exploring, detecting, and resolving different morphologic characteristics of lava tubes with GPR is the primary focus for this paper. Therefore, in this section we address critical questions of detecting (1) tube location (ceiling), (2) tube width (size), (3) floor (and therefore tube height), and (4) pillars, branches, and multiple levels in tubes. In each of the following four subsections we provide background information from previous studies on each of these factors individually followed by our results.

\subsection{Detecting Tube Location (Ceiling)}

\subsubsection{Background}

The ceilings of lava tubes and similar natural constructs defined by subsurface void spaces (tunnels, caves, and bridges) are generally good reflectors for GPR signals because of the large contrast in relative permittivity $\left(\varepsilon_{\mathrm{r}}\right)$ between void space and the surrounding environment creates a high-amplitude reflection (Davis \& Annan, 1989; Daniels, 2004; Cassidy \& Jol, 2009; Rowell et al., 2010; Conyers, 2013). On each GPR trace, following the high-amplitude return from the ceiling (interface of soil and air), a time interval devoid of strong returns is expected, corresponding to the travel time of waves through the void (Conyers, 2013; Rowell et al., 2010). If the lava tube is short in height, this time may be short compared to the radar wave period (as illustrated in Figure 2 void on right) because the wave travels $~ 1.5-3$ times faster in the void than in the surrounding rock (at velocities expected on Earth, the Moon, and Mars, see Table 1). Furthermore, in real lava tubes travel paths may be very complex, with multiple returns coming from fractures within the overburden, and diffracted energy returning from wall complexities and benches. Depending on cave depth and 
Table 1

Considered Electrical Properties of the Media in Our Synthetic Models for Earth, Mars, and the Moon

\begin{tabular}{llll}
\hline Media & Relative permittivity $\left(\varepsilon_{\mathrm{r}}\right)($ unitless $)$ & Velocity $(\mathrm{m} / \mathrm{ns})$ & Electrical conductivity $\delta(\mathrm{mS} / \mathrm{m})$ \\
\hline Host rock on Earth & 6.25 & 0.12 & 1 \\
Host rock on Mars & 4.5 & 0.14 & 3 \\
Host rock on the Moon & 3 & 0.17 & 0.25 \\
Basaltic wall lining & 7.4 & 0.11 & 10 \\
Free space & 1 & 0.3 & 0 \\
\hline
\end{tabular}

Note. The host rock relative permittivity $\left(\varepsilon_{\mathrm{r}}\right)$ are obtained from Picardi et al. (2004), Seu et al. (2004), Grimm et al. (2005), Haruyama et al. (2017), and Kaku et al. (2017). The third column includes average velocities for each material calculated based on the relative permittivity $\left(\varepsilon_{\mathrm{r}}\right)$ values.

dimensions, the first multiple from the ceiling itself may arrive during this expected "blank" time window. Conyers (2013) reports no continuous reflections recorded within the expected void space time, just some discrete low-amplitude reflections that contrast with high-amplitude planar reflections from the bounding basalt flows.

Reflections generated at the void interface should display reversed polarity compared to the direct wave that is recorded as the first arrival at the receiver. Since soil/rock has higher permittivity compared to air (e.g., Conyers, 2013; Miyamoto et al., 2005), the reflection coefficient at the rock to air interface is negative (Milsom \& Eriksen, 2013; Neal, 2004). In theory this polarity can be a useful diagnostic for determining material type. However, in lava tube cases, in reality, the interference patterns between multiple returns due to fractures in overburden and irregular ceilings are so complex that the polarity of the reflection generated from the void space is not readily identified. In this case the key to locating the lava tubes is to search for the high-amplitude reflection from the tube ceiling and to differentiate those reflections from other reflections in the radargrams (Conyers, 2013; Rowell et al., 2010).

\subsubsection{TubeX Results and Discussion}

At all crossings of LiDAR-mapped tubes, the expected high-amplitude reflections from the tube ceilings are clearly identifiable. Figures 8 and 9 demonstrate this on selected lines over both Skull and Valentine caves. We note that these GPR images are made with only very basic processing steps (dewow, static correction, and frequency filtering) and are not gained. The fact that no gain is applied to amplify the reflected amplitudes confirms that the ceiling signatures are relatively easy targets even without any further processing. We note that because the profiles in Figures 8 and 9 are plotted with a constant time-to-depth conversion and are not migrated, the ceiling responses are more complicated than the measured ceiling shape, with overlapping diffraction wings produced by discrete irregularities in the ceilings.

An important question for planetary exploration is whether there would be significant "false positives" for lava tubes, that is, whether density contrasts in subsurface layers would produce signatures that are very similar to that of lava tube ceilings. Figures 8 and 9 demonstrate that returns nearly as strong as the ceiling returns, at comparable depths, are observed in places (e.g., Line 1 on Figure 8 and Line 20 on Figure 9). We unfortunately cannot address this question directly, because bright off-cave reflections could represent returns of unmapped voids. For planetary exploration, such a question would require the acquisition of additional profiles at different angles. For example, the reflection on Line 1 (Figure 8) at $\sim 3 \mathrm{~m}$ below land surface and between 30 and $65 \mathrm{~m}$ along the profile shows the reverse polarity, expected from a ceiling. To determine if this could be a profile collected along the axis of a cave would require profiles collected at higher angles with respect to the tube direction compared to Line 1, which would be expected to show a curved ceiling.

Interestingly, we find that the radar wave velocity that best fits both the shapes of diffraction hyperbolas and the mapped depth to ceilings increases with distance from the cave opening on both Skull and Valentine caves. For time-to-depth conversion of GPR images at the Skull Cave (Figure 8, entrance on western end), wave velocity of $0.11,0.12,0.135,0.135$, and $0.14 \mathrm{~m} / \mathrm{ns}$ were used for Lines $76,75,74,1$, and 78, respectively. For Valentine Cave (Figure 9, entrance on southern end), GPR wave velocity of 0.1, 0.11, 0.12, 0.12, and $0.14 \mathrm{~m} / \mathrm{ns}$ were used for Lines 30, 29-2, 29-1, 20, and 25, respectively. This trend is observed even though profiles were collected on different days following different amounts of rainfall. (Radar wave velocity is much slower in water than in rock or air, so increased soil moisture will depress wave velocities.) We note 


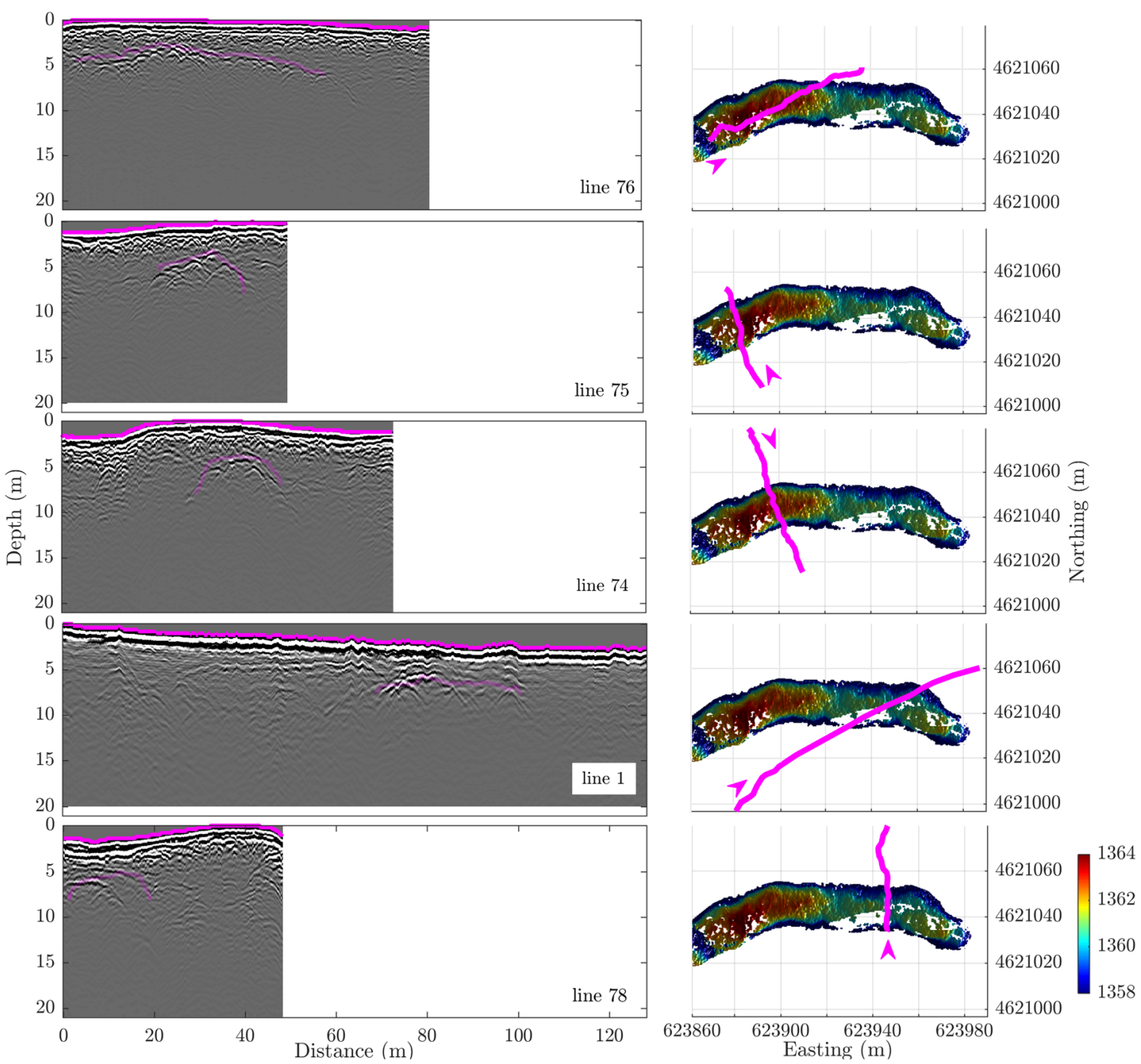

Figure 8. Left: Selected ungained 100-MHz GPR profiles over Skull Cave, showing that ceilings produce strong radar response with minimal data processing. Travel time to depth conversions and topographic corrections are done using constant velocity for each profile, derived from the GPR data, as described in text. The solid purple lines on GPR profiles indicate the LiDAR surface scan, and the transparent purple color shows the location of the cave ceiling from in-tube LiDAR scans. Right: Color shaded relief LiDAR map of cave ceiling elevation (meters above sea level) with corresponding GPR profiles location and direction marked in purple. White zones within the shaded relief map reflect data gaps in LiDAR scans.

that on both caves, both ceiling elevation and overlying ground surface elevation decrease with distance from the opening; that is, flow was downhill from the entrance in the mapped direction. There is no increase in overburden thickness except on the most northern profile on Valentine Cave (Figure 9, Line 25). Two possible explanations for the velocity trend are thus (A) higher water content is sustained in the overburden close to the cave entrance and decreases downhill; or (B) air-filled porosity increases, perhaps in the form of wider fractures or increased fracture density in the rock in the downflow direction. Both could be true, if water infiltrates more rapidly through more fractured rock overburden. Visual observations from within caves suggested that ceilings and walls were wetter near the entrances, supporting (A).

\subsection{Detecting Tube Width}

\subsubsection{Background}

Ideally, tube width is estimated from a GPR transect perpendicular to the long axis of the tube. (If a transect is parallel to the tube, only a high-amplitude planar reflection will be recorded from its ceiling (Conyers, 2013).) If profiles are run at oblique angles to the tube, the data will show the expected diffraction wings 


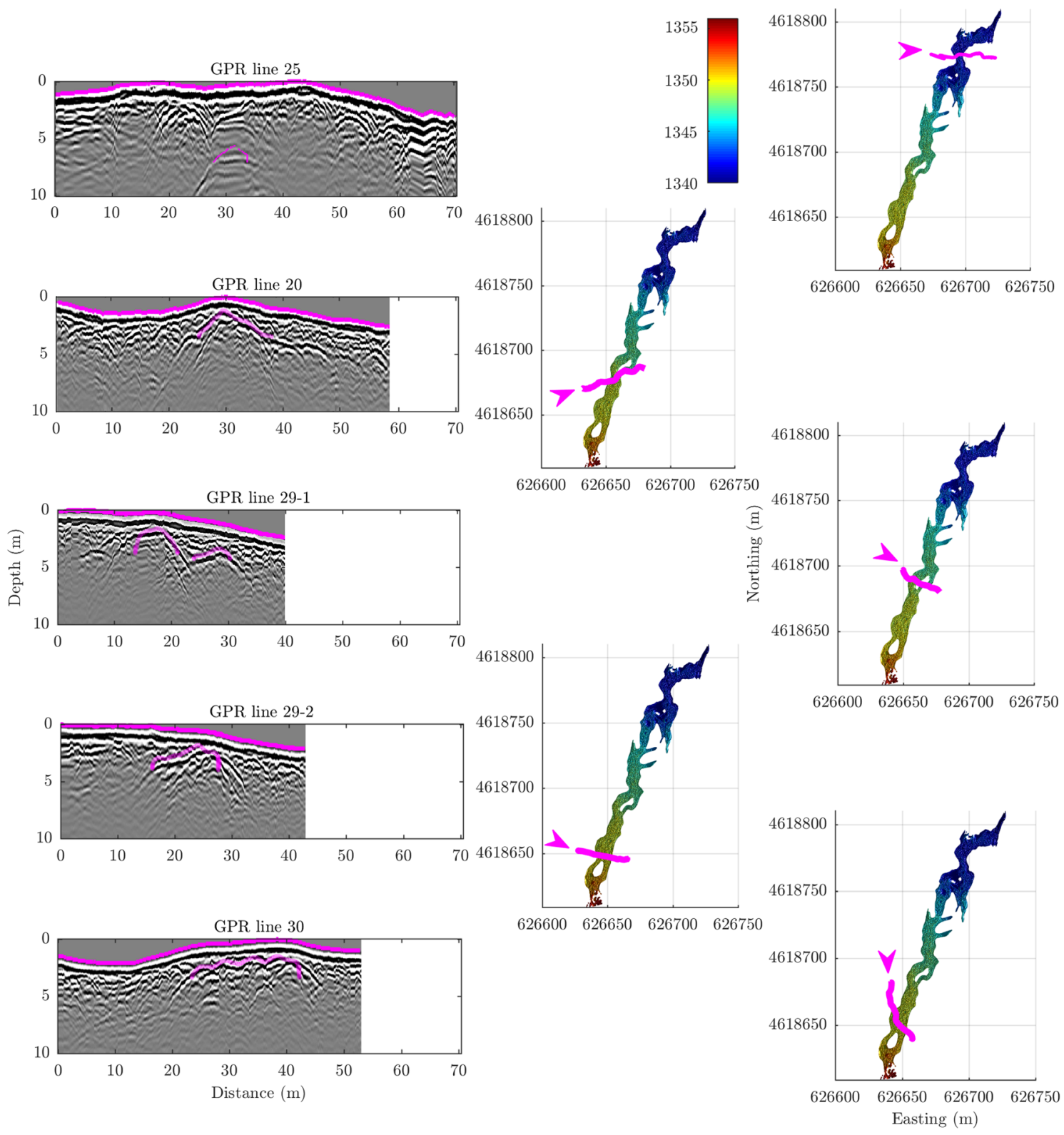

Figure 9. Left: Selected ungained 100-MHz GPR profiles over Valentine Cave, showing that ceilings produce strong radar response with minimal data processing. Travel time to depth conversions and topographic corrections are done using constant velocity for each profile, derived from the GPR data, as described in text. The solid purple lines on GPR profiles indicate the LiDAR surface scan, and the transparent purple color shows the location of the cave ceiling from in-tube LiDAR scans. Right: Color shaded relief LiDAR map of cave ceiling elevation (meters above sea level) with corresponding GPR profiles location and direction marked in purple. White zones within the shaded relief map mainly reflect pillars in LiDAR scans.

extending into traces acquired beyond the edges of the tube, but these diffraction hyperbola wings will not be properly migrated back into the correct ceiling position with 2-D migration algorithms. (2-D migration algorithms assume that reflections occur in the vertical plane of the profile, while ceiling returns from an oblique profile will come from out of plane.) In addition, GPR profiles should be long enough that they capture the full extent of the diffraction wings, for optimal migration. This extra distance is at least several times the tube depth. For example, as shown in Figure 2 and Line 29-1 in Figure 9, for tubes 1-2 $\mathrm{m}$ below surface, the ceiling signature extends some 5-7 $\mathrm{m}$ beyond the edge of the tube.

Collapsing the ceiling returns in the GPR time profile back to the true geometry, and then converting time to depth, requires migration. A variety of migration techniques are widely used in seismic and GPR data 


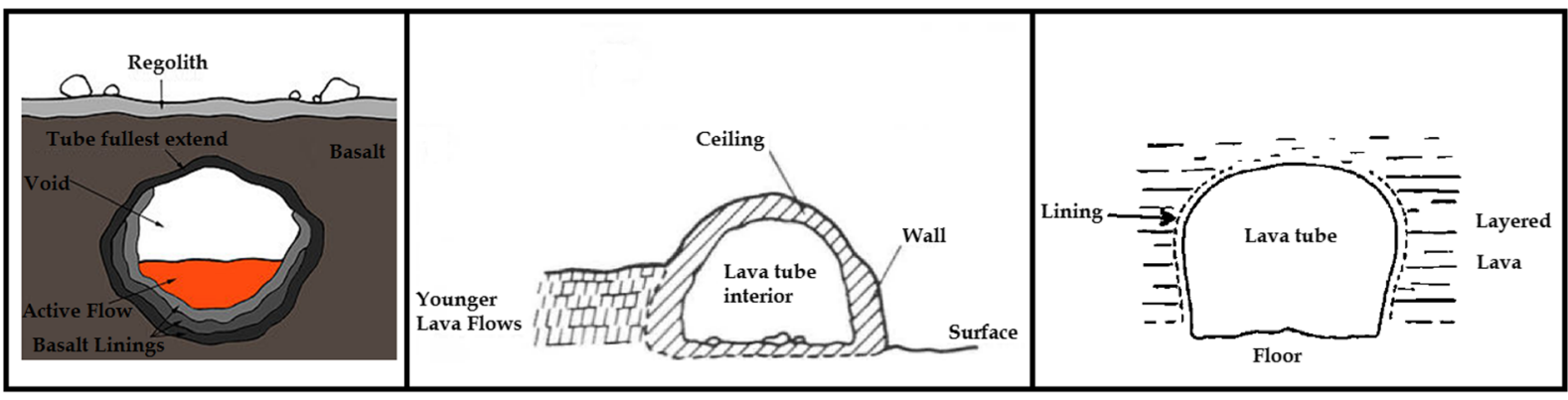

Figure 10. Three schematic lava tube cross sections from previous literature, which show the wall thickness, lining, and layers. Left: from https://en.wikipedia.org/ wiki/Martian_lava_tube Middle: from Greeley (1987). Right: from Atkinson et al. (1975).

analysis (e.g., Yilmaz, 1987; Daniels, 2004; Jol, 2008). Rowell et al. (2010) use a modified version of Gazdag (1978) phase-shift migration; after migration they report a tube width based on the lateral extent of the bright ceiling reflection.

We note that tube "width", defined in this way, is the lateral extent of the ceiling that returns significant amounts of radar energy. As ceiling slope increases from the crest to the sides of the tube, the further off the axis of the tube the GPR must be to record the reflected energy. (Where walls are smooth vertical, reflected energy travels downward and cannot be recorded at the surface.) With increasing off-axis distance the return is increasingly attenuated. Thus, the distance from the crest at which signal from the ceiling is lost depends on the shape of the ceiling, the depth of the tube, the overburden conductivity (which controls attenuation), and the directional radiation pattern of the emitted pulse. As a result, the migrated ceiling return can be considered a minimum width of the tube.

Because GPR is most sensitive to the subhorizontal part of the tube ceiling, it would be useful for tube explorers using GPR to have an idea how ceiling geometry relates to overall tube dimensions. We are not aware of any comprehensive descriptions of lava tube cross-sectional profiles in different settings. Schematic cross sections of tubes show various shapes of ceiling and walls, including walls that widen to the floor and walls that narrow to the floor (Figure 10). We anticipate that the full TubeX LiDAR data set will be useful for better extrapolating tube geometry from ceiling form; this topic is beyond the scope of this paper.

Although no energy is returned from smooth near-vertical walls, returns are expected from subhorizontal or jagged fracture edges, porosity changes, or lithology changes. Such changes in properties are in fact commonly described around the rim of lava tubes, as annotated in Figure 10. Such layers that rim lava tubes are referred to as lining in much of the literature, or simply tube walls (Greeley 1971; Atkinson et al., 1975; Greeley, 1987; Peterson et al., 1994; Grimes, 2002).

Atkinson et al. (1975) describe lava tubes with curved, cylindrical walls plastered with a congealed lava lining. In many places, the walls are discordant to the adjacent layered lava (Figure 10, right). Ollier and Brown (1965) interpret the layered lava as possibly produced by shearing planes formed during flow just before solidification. They conclude that the tubes developed as discordant, late-stage structures by a process of residual lava segregation. Cylinders of flowing lava developed and eroded some of the virtually solid layered lava to form the final tubes. Drained tubes were left as caves with a congealed lining.

Atkinson et al. (1975) studied the petrology of rock lining the lava tube walls and host basalt away from the tube walls. Interestingly, they found that the ferric-ferrous ratios attest to strong oxidation in the lining, several orders of magnitude higher than the surrounding lava. The lining was also distinguished by its vesicular structure, transverse to that of the adjacent host rock.

Contacts between such lining layers and the host rocks are expected to complicate the GPR returns from ceiling and floor of tubes. They may also cause returns from the side linings, if they are associated with complex geometrical boundaries. If they produce interpretable GPR returns, lava tube linings could thus be an advantage for lava tube exploration compared to other kind of voids. 

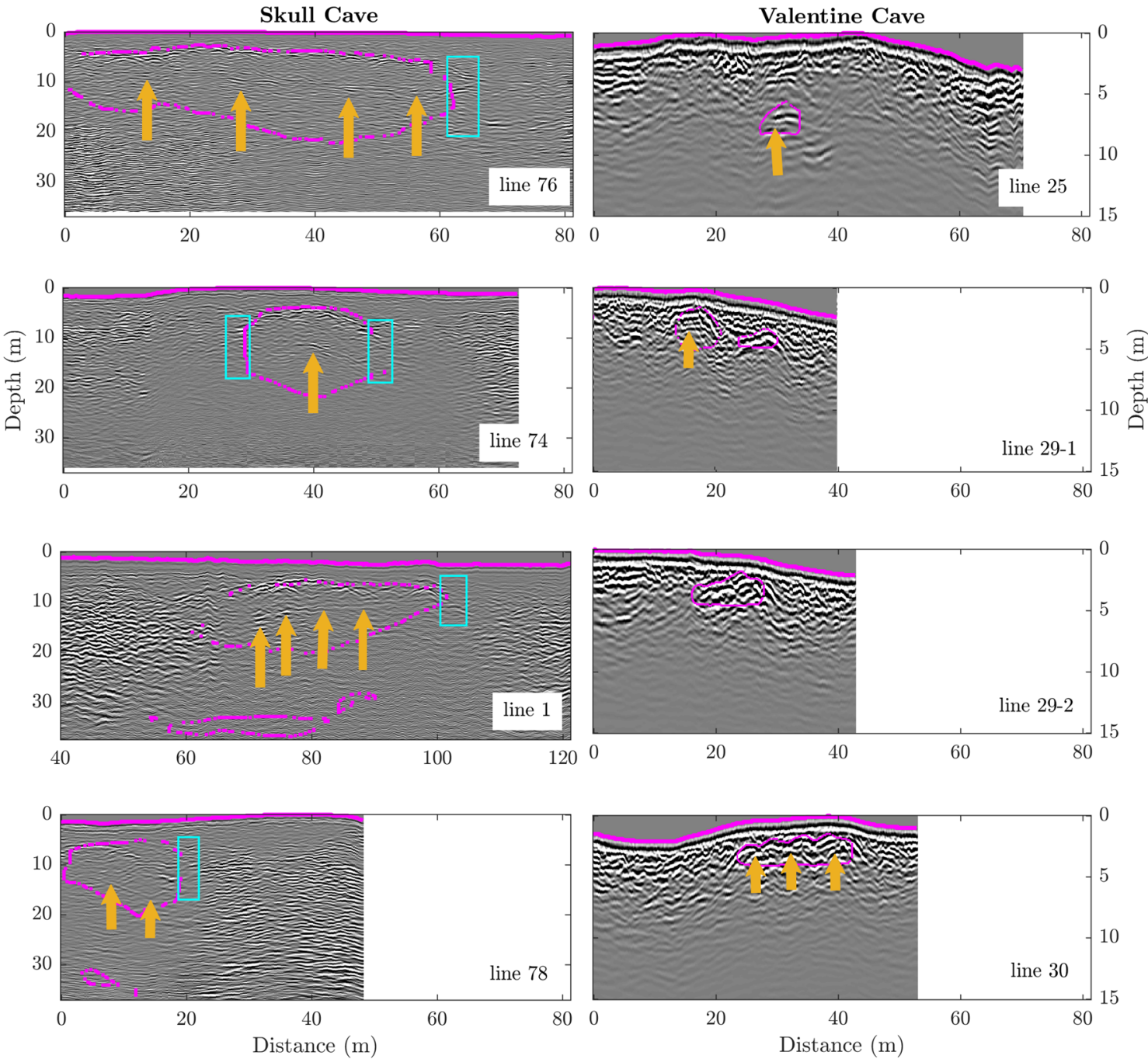

Figure 11. GPR profiles after constant-velocity Kirchhoff migration and a user-defined gain applied uniformly across each line. Velocities used in the migration are listed in the text and vary from line to line. Purple lines represent the location of the ground surface and tube walls from LiDAR scans. The blue rectangles indicate the locations of returns from tube walls or linings. The orange arrows indicate the reflections from the tube floors. The location of the tube floors is pulled up to an apparently higher elevation due to the constant-velocity migration used which ignores the velocity change of the signal in tube void. (See Figures 13 and 14 for the corrected depths after 2-D finite difference migration.) Left: GPR profiles on Skull Cave. See Figure 8 for unmigrated results on the same lines and locations. Right: GPR profiles on Valentine Cave. See Figure 9 for unmigrated results and locations.

\subsubsection{TubeX Results and Discussion}

Migrations of the GPR traverses over Skull and Valentine caves in LBNM illustrate the points discussed above on resolution of cave width. Figure 11 shows constant-velocity Kirchhoff migrations for selected lines shown in unmigrated data form in Figures 8 and 9. This migration method was chosen because it is fast compared to reverse-time migration and also is capable of migrating steep dip reflections (Zhu \& Lines, 1998). FK migration (e.g., Smitha et al., 2016; Yilmaz, 1987) is fast as well; preliminary tests show that for a few of the profiles in this study, FK migration can provide interpretable migrated images. However, we use Kirchhoff migration for all lines, as it successfully migrates all data for all lines shown here and has a uniform processing platform. Comparing the performance of the FK and Kirchhoff migrations is beyond the scope of this paper. After migration, the bright ceiling reflector corresponds well with the LiDAR-mapped ceiling geometry, and the lateral extent of the migrated ceiling return is a reasonable measure of the width of the cave. One exception is Line 78 from Skull Cave. This line starts at just over the edge of the cave and illustrates the problems with migrating data without having the necessary distance off the edge of the cave. Other misfits between migrated geometry and mapped width of ceiling can be plausibly attributed to 3-D effects, as 
cave geometry shows significant variability off the strike of the GPR profiles, so some of the ceiling returns are coming from points off the profile. In addition, the observation that individual lines are best migrated with different velocities suggests that there may be within-line velocity variability in the overburden that cannot be accounted for with constant-velocity migration. (The constant-velocity migration cannot collapse the floor to the correct position because it does not account for the faster wave velocity in the air-filled void.)

Figure 11 also shows that some migrated profiles show bright returns near the side walls of the cave, as highlighted with the blue boxes. (To identify the potential small hyperbolas generated by fractures and cracks in lining, however, one may find unmigrated images more suitable.) Many of these features fall slightly outside the mapped cave wall and hence may reflect discontinuities in the lining. These features are similar in amplitude to many returns from the host rock and so on their own are not diagnostic GPR signature. But where the fall at the edge of one low-amplitude zone corresponding to the air-filled void, they are indicative of the presence of a rough wall or lining.

\subsection{Resolving the Tube Floor (Tube Height)}

As the radar signal enters a void, it speeds up to the speed of light, and there is little attenuation of the propagating waves until they encounter the next surface that reflects energy. On the radar profile this is equivalent to a period of time of low-amplitude returns followed by a higher-amplitude return and then reflections more typical of rock boundaries, which is thus an indication of a void (Conyers, 2013). In practice, the floor signal can be subtle or difficult to detect. The floor return can arrive soon after the ceiling reflection if the tube has low height (because of the fast air travel time). In addition, energy from the surface antenna can move into the void space at a variety of angles as it refracts at the ceiling and can be reflected, possibly from projecting stones in the walls of the void, or from shelves, or rough floor, which act as small focusing surfaces (Conyers, 2013).

As described above, projecting the floor signature to its correct depth can only be achieved by 2-D migrations that consider the realistic velocity structure (with lateral and vertical velocity variations) of the subsurface. Before discussing the 2-D migration (section 4.3.2), we address the question whether floor depth can be crudely estimated from minimally processed data.

\subsubsection{Tube Height Estimates From Unmigrated Data}

Some profiles show a sufficiently distinct floor arrival that it can be recognized in the unmigrated data. Line 74 at Skull Cave is an example (Figure 12). At $40-\mathrm{m}$ distance, the reflection from the ceiling is recorded at $60 \mathrm{~ns}$, and the floor signature is recorded at $\sim 170 \mathrm{~ns}$ two-way travel time. Therefore, the one-way travel time between ceiling and floor is $1 / 2(110 \mathrm{~ns})=\sim 55 \mathrm{~ns}$ which is equivalent to $\sim 16.5 \mathrm{~m}$ in free space. This tube dimension matches the LiDAR data (Figure 11) which show heights of 15-18 m across the central part of the cave.

\subsubsection{2-D Migration}

The 2-D migration needed to more fully and more accurately recover the floor position is challenging because the velocity change at all rock-air interfaces is extreme (a factor of 2-3), and thus, the position of the ceiling must be well defined in the velocity model. The lateral velocity variations on the sides of the tube are similarly extreme, and many migration schemes cannot simultaneously handle the two problems of imaging of steep dips and imaging in media with arbitrary velocity variations in all directions (e.g., Yilmaz, 1987; Ristow \& Rülh, 1994). For example, phase-shift migration is accurate for nearly all dips but is limited to very simple velocity functions (Ristow \& Rülh, 1994). Among different possible migration methods, finite difference migration has potential for treating both steeply dipping and sharp variations in velocity (Ristow \& Rülh, 1994).

Comparison of methods on the LBNM GPR profiles showed that the finite difference method produces superior results to that of phase-shift migration (Esmaeili et al., 2018a) and Kirchhoff migration. Figure 13 shows results for two migration scenarios with the finite difference method. In both scenarios the velocity in each cell in the model is defined as rock or air, where the rock velocity on each is based on the average of best fits to diffraction hyperbolas and listed in section 4.1.2. In theory, defining a heterogeneous velocity structure for rock could improve the migration; in practice, this is difficult from common-offset GPR data with a limited number of clear diffraction hyperbolas. The velocity of the wave inside the void is assumed to be $0.3 \mathrm{~m} / \mathrm{ns}$ (velocity of light in free space). 


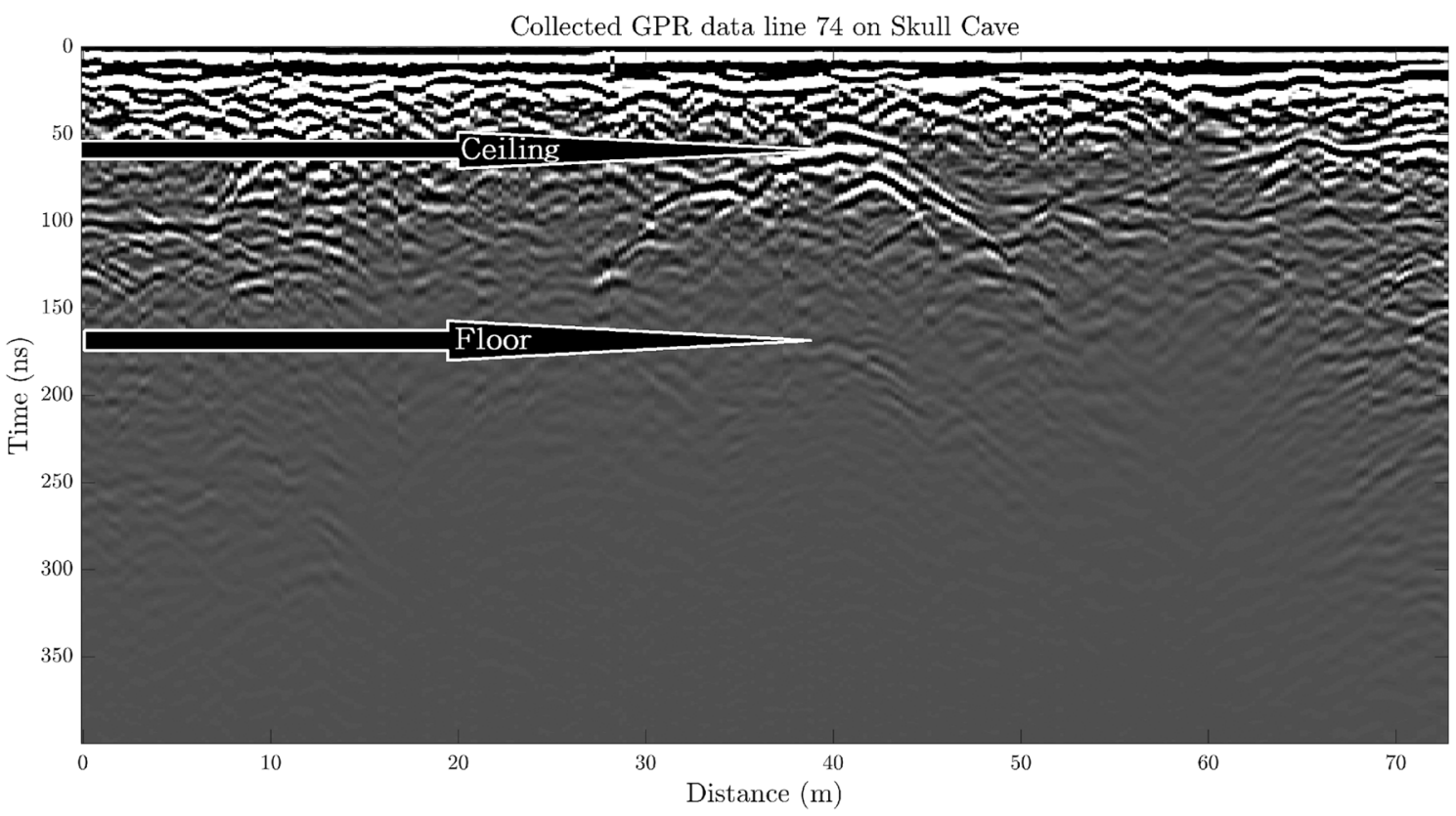

Figure 12. Skull Cave GPR Line 74; unmigrated GPR data on Line 74 on Skull Cave. See Figure 8 for location. The arrows point to the reflections from the ceiling and the floor. The down-up travel time through the cave (110 ns) corresponds to $16.5 \mathrm{~m}$, in good agreement with the mapped cave height.

In the first scenario, we define the velocity model based on LiDAR data. We take advantage of the surface and in-tube LiDAR data and create 2-D velocity models based on cross sections of LiDAR data (aligned with GPR profiles). Results are shown in the plots on the left side of Figures 13 and 14 for Skull and Valentine caves, respectively. Clearly, when the correct lava tube boundaries are incorporated in the velocity model, the migrated GPR data show strong returns that closely follow (to within 1- to 2-m depth) the ceiling and floor. The notable exception is Line 78 on Skull Cave, which fails to properly capture the ceiling and shows significant returns in the window that should represent the air void. This failure for Line 78 could be a result of a very irregular profile, required as the GPR had to be moved around bushes and rocks, with a significant turn during data collection while over the cave. The resulting ceiling reflection may be distorted. We note also that on all lines the floor reflection is best recovered for the central part of the floor, with weaker response from the edges where the floor meets the walls.

In the second scenario, we assume the true exploration condition, namely, that the cave geometry is unknown. The plots on the right hand sides of Figures 13 and 14 show the results of migration, assuming that the surface topography is measured, but the lava tube is unknown. In this case, the picks of the ceiling reflections are used to define the ceiling boundary in the velocity model. These ceiling reflections are subjectively identified based on the continuity of reflectors, with an underlying zone of low-amplitude returns. Average best fitting rock velocities are derived for each profile, as before. Then the zone of air velocity beneath the ceiling is assumed to extend to depth, with vertical side boundaries. In this model reflections from the floor, which have traveled through the overburden and then through the void, should theoretically migrate to the true floor depth. Any returns from below the floor will be distorted and not interpretable.

Figure 13 (right column) shows that this method recovers a less prominent but detectable return from the floor position for Skull Cave, except for the anomalous Line 78. It is interesting that the Skull Cave floor is recovered, even though the floor of the central part of the tube is covered in blocks up to $4 \mathrm{~m}$ that are a significant fraction of the radar wavelength in the void (approximately $3 \mathrm{~m}$ for a $100-\mathrm{MHz}$ center frequency pulse). In comparison, Figure 14 (right column) shows that migration from the ceiling picks alone is less successful for floor recovery on Valentine Cave, which was much smoother (a ropy lava flow, generally free of blocks). The reason is presumably that the Valentine Cave tube height is itself close to the $\sim 3$-m wavelength in the cave, which creates mixed and inseparable reflections from ceiling and the floor in GPR data which in turn makes migration complicated and less successful. There could be multiple reasons for the absence of a 

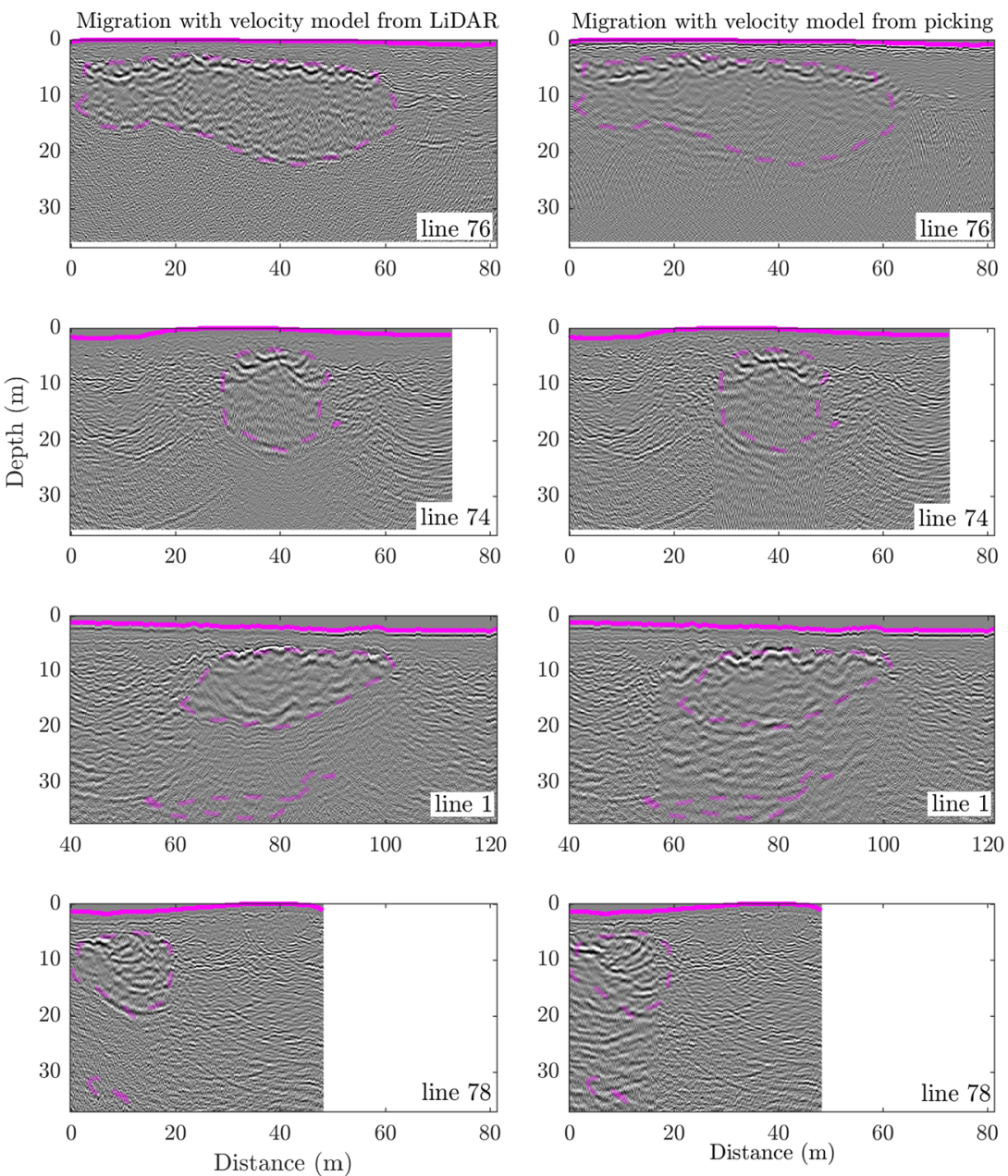

Figure 13. Migration of GPR profiles collected on the Skull Cave. Plots on the left hand are created with the 2-D velocity model built from LiDAR data and on the right hand with the 2-D velocity model from ceiling picking.

clear floor return, including the floor roughness, low cave height (overlapping floor and ceiling returns), the shape of the cave ceiling (refracting energy away from the floor), and the presence of conductive material at the cave floor. The floor textures of Valentine and Skull caves are clearly different. The Valentine floor is smooth and almost flat, creating a sharper floor reflection. In contrast, the irregular blocks covering the Skull Cave floor would be expected to scatter energy, producing a less coherent reflection.

Clearly, the migrations with the floor accounted for in the velocity structure (left plots on Figures 13 and 14) have better resolution than those without (right plots on Figures 13 and 14). One way to improve the resolution in the real-world scenario where the floor is unknown would be to estimate a floor position based on the ceiling shape and dimension and then invert for a best fitting floor shape and position that maximizes a coherent return. Such an inversion is beyond the scope of this paper.

\subsection{Detecting Pillars or Multiple Levels Within Tubes}

GPR Line 29-1 on Valentine Cave crosses a pillar that separates two branches of the cave (Figure 8, appears in cross section as two neighboring tubes). As Figures 9, 11, and 14 show, the two independent roof sections are visible as having distinct arched forms; presumably, a pillar supports the inner part of each arch. However, the migrated images (Figures 11 and 14) do not unambiguously show two distinct separate ceilings. So from the GPR data alone the presence of the pillar is indicated but not directly visible. We note that this pillar ( 4-m diameter with ceiling at 2.5-m depth) has similar dimensions to the radar wavelength in air. Any comparable but larger feature should be easier to resolve. 

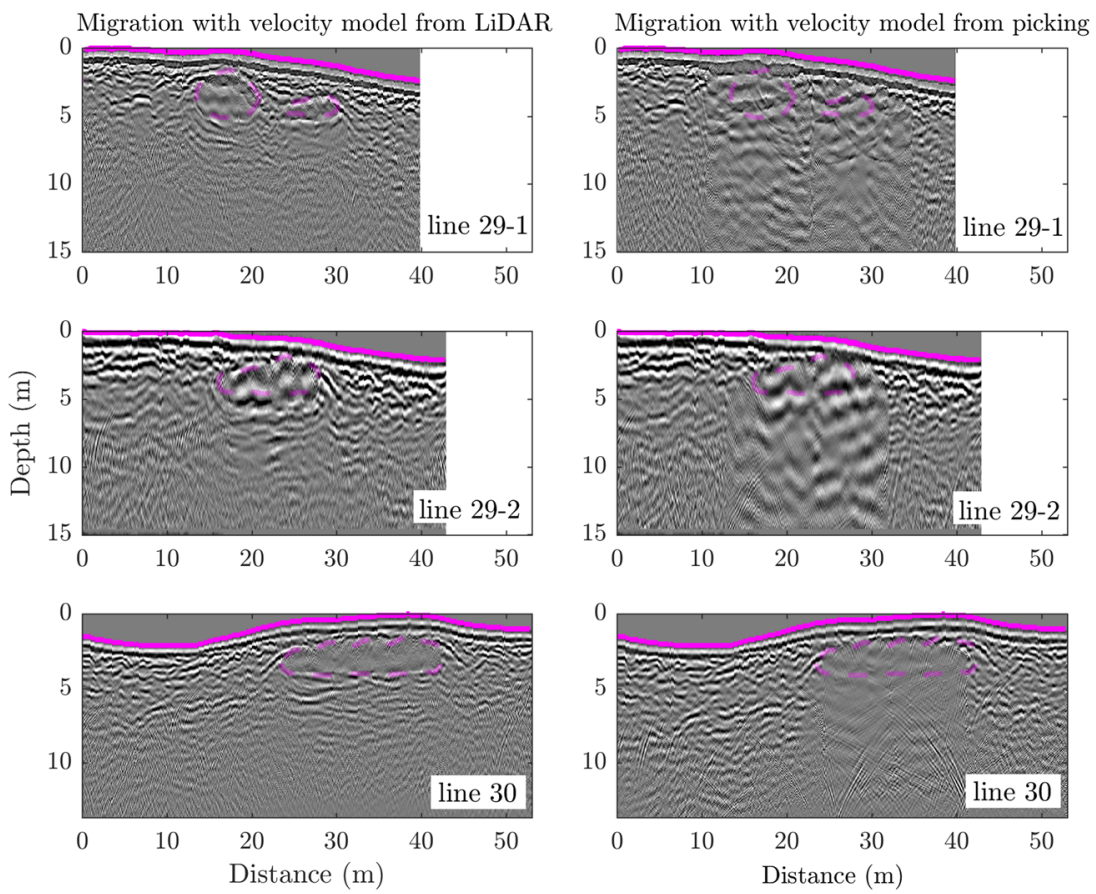

Figure 14. Migration of GPR profiles collected on Valentine Cave. Plots on the left hand are created with the 2-D velocity model built from LiDAR data and on the right hand with the 2-D velocity model from ceiling picking.

GPR Lines 1 and 78 on Skull Cave (Figure 5) run over the cave at a location where it has multiple levels. As seen in Figures 8 and 13, there is no indication of the lower level in the unmigrated or migrated data (Figure 13, LiDAR purple geometry model indicates the location of the lower floor on both lines). This is expected as the floor reflection of the upper level tube is relatively weak; any deeper reflections will only be more attenuated and scattered by increasing complex travel paths.

\section{Implications for Lava Tube Detection on the Moon or Mars}

\subsection{Background}

Lava tubes also provide potential exploration targets. Surveys of lunar sinuous rilles (e.g., Hurwitz et al., 2012) and lava tubes and associated collapse pits (e.g., Coombs \& Hawke, 1992; Haruyama et al., 2009; Robinson et al., 2012; Wagner \& Robinson, 2014) can be used to provide recommendations for the roles that lava tubes could play in crewed exploration. These studies demonstrate that, assuming that astronauts could gain entrance to the tubes through collapse features, lava tubes would shield crews from dangerous radiation, rapidly fluctuating and dramatic temperature swings, and even small meteorite impacts.

Mounting evidence from the SELENE, LRO, and GRAIL spacecraft suggests the presence of vacant lava tubes under the surface of the Moon. SELENE Lunar Radar Sounder results provided evidence of subsurface void space within the Marius Hills region of the Moon with 10s m of overburden (Kaku et al., 2017). In the same region, GRAIL gravity data also point to subsurface mass deficiencies that are consistent with tube-like voids larger than a kilometer in width (Chappaz et al., 2017). Under lunar gravity conditions (lunar g H 1/6 terrestrial $g$ ), lava channels and tubes an order of magnitude larger in each size dimension, that is, hundreds of meters wide by hundreds of meters or more deep and tens of kilometers long, might be stable within the subsurface (Angelis et al., 2002; Blair et al., 2017).

As Martian gravity is intermediate (2/5 terrestrial $g$ ), stable tube sizes are likely also intermediate. This is supported by observations of curvilinear collapse pit chains along axial ridges of lava flows within the Tharsis Volcanic Province, where pit widths are usually more than $100 \mathrm{~m}$ and often a few hundreds of meters across (Bleacher et al., 2011; Bleacher et al., 2017; Crown et al., 2019; Cushing et al., 2007). Martian tube systems are also longer than their Earth counterparts, often reaching $>100 \mathrm{~km}$ in length (Bleacher et al., 2017), 
and could be as long as 700 to $+1,000 \mathrm{~km}$ (Keszthelyi, 1995) which corresponds to the longer travel distances of basalt lava flows expected on Mars due to eruption dynamics (Wilson \& Head, 1994). While on first order, lower gravity would increase tube stability, observations have shown that the percent tube length that has collapsed on studied tubes on Mars is higher than what is observed on Earth (Sauro et al., 2018), though this could be because tubes on Earth are completely obliterated over shorter timescales than on Mars.

According to Daga et al. (2013), one problem in lava tubes study on Mars or the Moon is that, once located, it may be very difficult to gain access. The most obvious solution would be to locate a natural opening extending from a collapse site. It may be possible to locate such an opening from the high-resolution orbital survey, if properly tasked. Even then, it is not certain that tubes will be structurally sound or that collapsed pits provide accessible ingresses to tubes. GPR can therefore serve an important role in qualifying the roof structure and cave geometry beyond the potential pit entrance.

Studies of GPR performance on Mars have found that although the intrinsic absorption may be low in the total absence of liquid water, scattering due to faults, fractures, and even simple stratigraphic layering may strongly influence achievable depths of investigation (Grimm et al., 2005). A very thick and highly magnetic dust layer covering the lava flows may attenuate the signal faster at higher frequencies. Lower antenna frequencies are less sensitive to thin layers of magnetic dust (Stillman \& Olhoeft, 2008). Currently, the Radar Imager for Mars' Subsurface Experiment (RIMFAX) is being developed for inclusion on the Mars 2020 NASA Rover. This GPR, will have working frequencies between 150 and $1200 \mathrm{MHz}$, has an expected depth of penetration to $10 \mathrm{~m}$ or more (Hamran et al., 2015). Our study, which implements $100-\mathrm{MHz}$ frequencies into more absorbing media on Earth, therefore provides a strong analog to the lower working frequencies used on RIMFAX. Future missions with similar GPR instruments to environments with expected tubes would likely be able to observe voids of interest on the Martian surface. GPR performance on voids within resistive $\mathrm{CO} 2$ ice free of conductive inclusions should be equivalent to the void-in-rock discussed here, or even better if the ice matrix is more homogeneous.

Heggy et al. (2006) conducted field studies at Craters of the Moon National Monument (Idaho, USA) focused on potential mapping in mafic terrains as an analog to the Martian case with low-frequency GPR. Their results show that low-frequency GPR (16 to $100 \mathrm{MHz}$ ) has the potential to probe the shallow subsurface to depths of $\sim 10$ to $80 \mathrm{~m}$ in terrestrial arid volcanic terrains containing mafic basalts and pyroclastic deposits. If the geological and geophysical complexity of the Martian subsurface is similar to that observed at Craters of the Moon, Idaho, then the maximum sounding performance of orbital radar instruments is likely to be strongly influenced by scattering, as well as magnetic and dielectric, losses. They state that effective dynamic ranges of $\sim 30 \mathrm{~dB}$ (similar to the characteristic of MARSIS, Picardi et al., 2004) and $50 \mathrm{~dB}$ (similar to SHARAD, Safaeinili et al., 2001; Seu et al., 2004; Phillips et al., 2005) suggest that average penetration depths on the order of 500 and $50 \mathrm{~m}$, respectively, may be more typical of those achieved in volcanic terrains on Mars. The GPR data collected by Yutu rover on the surface of the Moon in 2014-2015 are reported to penetrate to $+300 \mathrm{~m}$ for the $60-\mathrm{MHz}$ antenna and $\sim 10 \mathrm{~m}$ for the 500-MHz antenna (Xiao et al., 2015).

\subsection{Forward Model Results}

In order to compare the expected GPR response on the surface of the Moon and Mars, we simulate the GPR response over the equivalent of Valentine Cave Line 29-1 (Figure 3), under rock parameters estimated for the Moon and Mars (Figure 2). The in-tube LiDAR data do not include the lining wall; we have added a lining around the tubes (black color on Figure 2 top) to add more realistic complexity to the model. But no additional fracturing or heterogeneities are assumed in the overburden or host media.

The rock/regolith parameters are listed in Table 1, derived from Picardi et al. (2004), Seu et al. (2004), Grimm et al. (2005), Haruyama et al. (2017), and Kaku et al. (2017). We note that the simulated tube is an order of magnitude smaller than the lava tubes inferred from orbital radar and gravity on the Moon, but we show the comparison in order to illustrate simply anticipated comparative effects of the planetary media. Additionally, tubes of this size are smaller than can be observed with SELENE radar data and GRAIL gravity models, so the lack of observations is not evidence against the existence of smaller "Earth-sized" tubes. The antenna center frequency is assumed to be $100 \mathrm{MHz}$, similar to the antenna used in this research and in between the range of 60- and 500-MHz antennas on the Chang'E-3 rover (Xiao et al., 2015) and slightly lower than the minimum working frequency of RIMFAX (Hamran et al., 2015). The unmigrated results are shown 

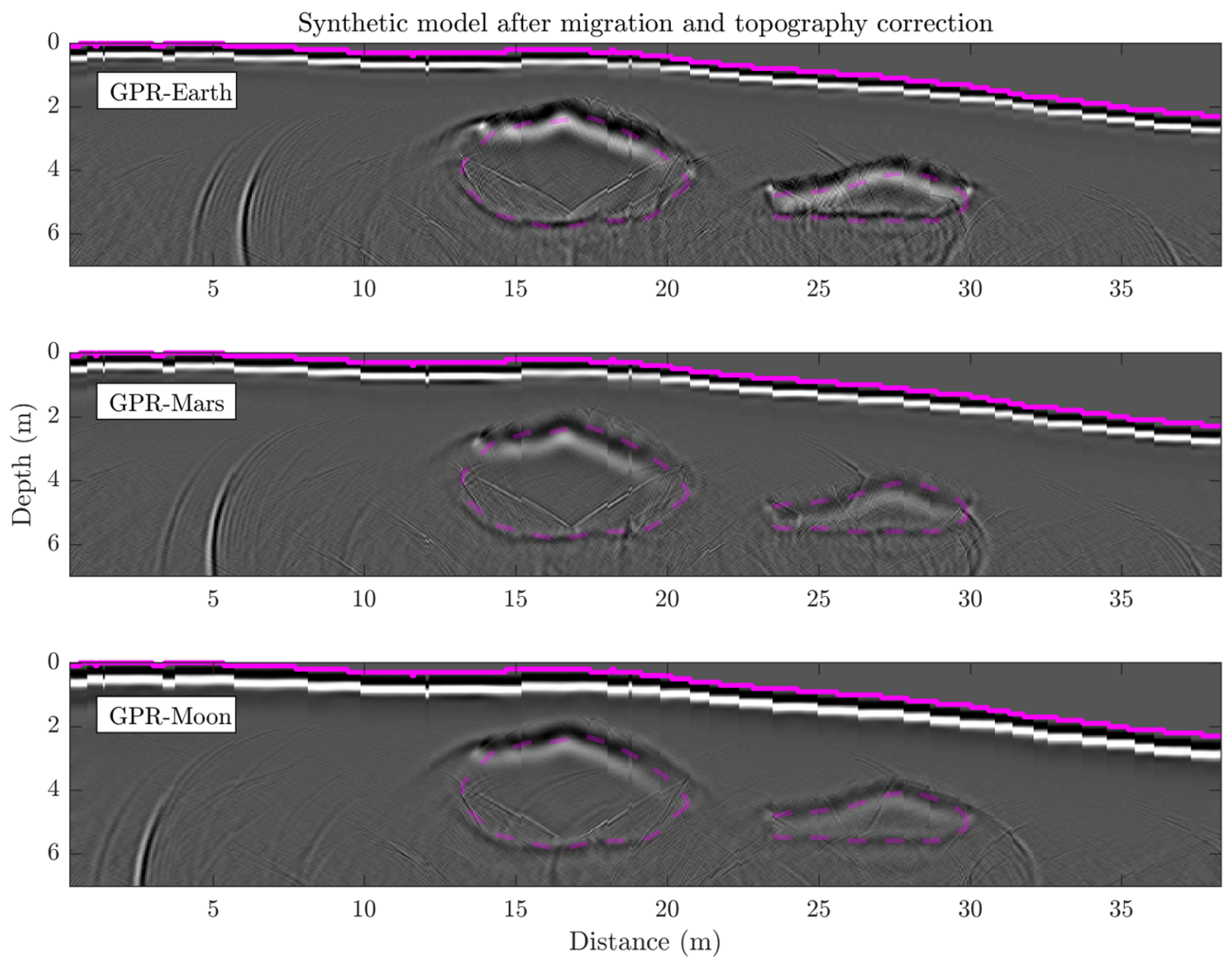

Figure 15. 2-D finite difference migration results for (top) synthetic GPR data on Earth, (middle) synthetic GPR data on Mars, and (bottom) synthetic GPR data on the Moon. Both ceiling and floor of both tubes are recovered after migration.

in Figure 2; the migrated results are shown in Figure 15 (band-pass filter is applied before migration to reduce noise level).

Considering the moisture in rocks on the Earth surface, high electrical permittivity is expected. As seen in Table 1, the host rock on Earth is set to a relative permittivity $\left(\varepsilon_{\mathrm{r}}\right)$ (i.e., the dielectric constant, the ratio of the electrical permittivity to that of free space) of 6.25 (calculated from the collected GPR data on Valentine Cave). Martian and lunar media are expected to be much dryer and therefore with lower relative permittivity $\left(\varepsilon_{\mathrm{r}}\right.$ ). The three different synthetic data sets are created using gprMax2D (Giannopoulos, 2005) to mimic the GPR response of this synthetic model on Earth, Mars, and the Moon for a 100-MHz Ricker wavelet pulse.

Migration on the synthetic data follows the procedure of the migration with LiDAR data described in section 4.3.2. We assume that rock is uniform and did not account for wall thickness and velocity difference between the host rock and wall lining material on all cases of Earth, Mars, and the Moon. 2-D finite difference migration is still successfully able to recover both tube ceiling and floor on all models since a very good, but not perfect, velocity model is used (Figure 15). Small not-collapsed disturbances are caused by not accounting for the velocity of the wall lining material.

The faster lunar and Martian radar travel speeds somewhat compress the arrival times of the returns from the planetary tubes relative to that of the Earth (Figure 2). The selected simulated rock materials on Mars and the Moon have higher electrical conductivity values and therefore more attenuation due to the conductivity values. Xiao et al. (2015) report reflections from +300 m deep in the GPR data collected by Yutu rover's $60-\mathrm{MHz}$ channel on the surface of the Moon. The similarity of the three models suggests that the conclusions of the LBNM surveys can be extrapolated to lunar and Martian scenarios without dramatic differences. In fact, the differences between the three models are much less than the difference between the synthetic "lava tube lining" model (Figure 2) and the real-world Valentine Cave crossing that the model was built to simulate (Figure 9 Line 29-1). The differences show the enormous complexity in the signal generated by heterogeneities in the host rock, particularly the overburden, and 3-D effects. Potential scattering 
within the host rock, external to the tube, due to regolith and rock heterogeneity, is expected to be the primary resolution limitation. Scattering from such heterogeneities may increase signal attenuation in subsurface and therefore higher losses of energy. Additional effects that might change electromagnetic characteristics of lunar or Martian soil include, for example, temperature, UV exposure, triboelectric effects due to local dust storms, and the probable presence of evaporites and clays in the Martian soil (Gooding, 1992; Heggy et al., 2006; Olhoeft, 1991; Stillman \& Olhoeft, 2005).

Migrating GPR data in order to recover the floor will be more successful on bigger tubes (e.g., the lunar lava tubes) since the dimensions of the tube would be much bigger than the wavelength of the signal (similar to Skull Cave results in this study). Smaller tubes are challenging to fully recover due to their comparable size to the wavelength (e.g., Valentine Cave).

\section{Conclusions}

GPR surveys over lava tubes at LBNM, CA, USA, confirm that surface-based GPR surveys would be a nondestructive and fast method for identifying tube segments appropriate for use in planetary exploration. Our results show that GPR, if in the penetration range, is successful in identifying lava tubes because of the high contrast between electrical properties of free space/air and the host rock. Ceiling reflections are found to have high amplitudes with distinctive continuity, so they are identifiable. The amplitude of GPR returns in the time following the ceiling reflections is low, presumably due to the absence of returns from the void and strong reflectivity of the rock/void boundary. This produces blank or "faded" zones below the ceiling return. From the ceiling return width, a rough estimate of the tube width can also be obtained. In addition, some lava tube wall linings at LBNM are inferred to diffract GPR energy, giving additional information about wall position. (Smooth, uniform, and vertical linings fail to diffract energy upward, which makes them invisible to GPR.)

Recovery of the correct floor depth requires applying migration techniques that take into account the lateral and vertical velocity changes in the subsurface, especially since the velocity of wave in host rock is significantly slower than inside the void. The migration works well for both Skull and Valentine caves when the velocity model is defined based on LiDAR-derived tube geometry. For the planetary exploration scenario, ceiling picks can be used to define the top of the air zone, permitting recovery of the approximate floor position for the central part of the cave. The velocity model based on ceiling identification is a key to the success of migration in floor recovery.

The LBNM Valentine Cave results show that proper recovery of the floor geometry is difficult when the cave dimension is comparable to the radar wavelength. However, lava tubes on the Moon and Mars are anticipated to be significantly larger than the terrestrial analogs imaged here, and therefore, higher-frequency GPR antennas (i.e., shorter wavelengths) can be used to resolve the depth and general shape of the floor. Broadband multiple frequency antennas can be helpful in increasing the resolution of the GPR images, possibly leading to a more robust characterization.

\section{Ongoing Work}

The effect of the wavelength on the data can make the interpretation challenging specially for smaller caves. Applying deconvolution techniques, such as Sparse Blind Deconvolution (Jazayeri et al., 2019), could help reduce the effects of the source wavelet, leaving behind the impulse response of subsurface layers, thereby sharpening the image and improving resolution. Ongoing research also examines the possibility that full-waveform inversion of the data for cave boundaries (Jazayeri et al., 2018) could yield higher-resolution subsurface models.

As a part of this project, we will create a library of different lava tube geometries and their corresponding GPR images from both migrated and unmigrated sections. The GPR image library will include tubes of different heights, widths, shapes, and structures (e.g., pillars), plus a variety of floor textures (e.g., smooth, ropey, and rubble) and overhead thickness. This library will be an asset for determining the utility of and interpreting GPR profiling in mapping a tube-rich environment. The image library will incorporate results from other caves as well. 


\section{Acknowledgments}

This work was funded by the NASA-PSTAR program. We would like to thank the staff at Lava Beds National Monument, CA, for their cooperation during data collection. We greatly appreciate Nasser Kazemi for his extensive help with the migration and Nicole Whelley for help with data collection. We thank Punnet Singh for her assistance with literature review and Frankie Enriquez for LiDAR data analysis. The manuscript benefited significantly from a constructive review by Glen Cushing. The data used in this manuscript can be found online (https://doi.org/10.5038/data geo.00001) (Esmaeili, 2019).

\section{References}

Angelis, D. G., Wilson, J. W., Clowdsley, M. S., Nealy, J. E., Humes, D. H., \& Clem, J. M. (2002). Lunar lava tube radiation safety analysis. Journal of Radiation Research, 43(Suppl), S41-S45.

Atkinson, A., Griffin, T. J., \& Stephenson, P. J. (1975). A major lava tube system from Undara Volcano, North Queensland. Bulletin Volcanologique, 39(2), 266-293.

Bell, E., Schmerr, N., Young, K., Whelley, P., Garry, W., Kruse, Esmaeili, \& Jazayeri, S. (2018, March). Characterization of lava tubes with magnetometry. In Lunar and Planetary Science Conference (Vol. 49).

Bernold, L. E., \& Immer, M. (2004). Ground penetrating radar technology to locate plastic pipes and lava tubes. In Proceedings of the Ninth Biennial ASCE Aerospace Division International Conference on Engineering, Construction, and Operations in Challenging Environments (pp. 24-31).

Blair, D. M., Chappaz, L., Sood, R., Milbury, C., Bobet, A., Melosh, H. J., et al. (2017). The structural stability of lunar lava tubes. Icarus, 282, 47-55.

Bleacher, J. E., Orr, T. R., Andrew, P., Zimbelman, J. R., Hamilton, C. W., Garry, W. B., et al. (2017). Plateaus and sinuous ridges as the fingerprints of lava flow inflation in the Eastern Tharsis Plains of Mars. Journal of Volcanology and Geothermal Research, $342,29-46$.

Bleacher, J. E., Richardson, P. W., Garry, W. B., Zimbelman, J. R., Williams, D. A., \& Orr, T. R. (2011, March). Identifying lava tubes and their products on Olympus Mons, Mars and implications for planetary exploration. In Lunar and Planetary Science Conference (Vol. 42, p. 1805).

Calvari, S., \& Pinkerton, H. (2004). Birth, growth and morphologic evolution of the 'Laghetto' cinder cone during the 2001 Etna eruption. Journal of Volcanology and Geothermal Research, 132(2-3), 225-239.

Carr, M. H. (1974). The role of lava erosion in the formation of lunar rilles and Martian channels. Icarus, 22(1), 1-23.

Cashman, K. V., Soule, S. A., Mackey, B. H., Deligne, N. I., Deardorff, N. D., \& Dietterich, H. R. (2013). How lava flows: New insights from applications of lidar technologies to lava flow studies. Geosphere, 9(6), 1664-1680.

Cassidy, N. J., \& Jol, H. M. (2009). Ground penetrating radar data processing, modelling and analysis. Ground penetrating radar: Theory and applications, 141-176.

Chappaz, L., Sood, R., Melosh, H. J., Howell, K. C., Blair, D. M., Milbury, C., \& Zuber, M. T. (2017). Evidence of large empty lava tubes on the Moon using GRAIL gravity. Geophysical Research Letters, 44, 105-112. https://doi.org/10.1002/2016GL071588

Conyers, L. B. (2013). Ground-penetrating radar for archaeology. Walnut Creek, California: AltaMira Press.

Coombs, C. R., \& Hawke, B. R. A. Y. (1992). A search for intact lava tubes on the Moon: Possible lunar base habitats.

Crown, D. A., Scheidt, S. P., \& Berman, D. C. (2019, March). Distribution and morphology of lava tube systems on the western flank of Alba Mons, Mars. In Lunar and Planetary Science Conference (Vol. 50).

Cushing, G. E. (2012). Candidate cave entrances on Mars. Journal of Cave and Karst Studies, 74(1), 33.

Cushing, G. E., Titus, T. N., Wynne, J. J., \& Christensen, P. R. (2007). THEMIS observes possible cave skylights on Mars. Geophysical Research Letters, 34, L17201. https://doi.org/10.1029/2007GL030709

Daga, A., Allen, C., Battler, M. M., Burke, J. D., Crawford, I. A., Léveillé, R. J., et al. (2013). Lunar and Martian Lava Tube Exploration as Part of an Overall Scientific Survey.

Daniels, D. J. (Ed.). (2004). Ground penetrating radar (Vol. 1). Iet.

Davis, J. L., \& Annan, A. P. (1989). Ground penetrating radar for high resolution mapping of soil and rock stratigraphy 1. Geophysical Prospecting, 37(5), 531-551.

Donnelly-Nolan, J. M. (2010). Geologic map of Medicine Lake volcano, northern California: U.S. Geological Survey Scientific Investigations Map 2927, pamphlet 48 p., 2 sheets, scale 1:50,000, https://pubs.usgs.gov/sim/2927/.

Donnelly-Nolan, J. M., \& Champion, D. E. (1987). Geologic map of Lava Beds National Monument, northern California. USGS Misc. Investigations Series Map I-1804, 1:24,000.

Esmaeili, S. (2019). TubeX data. DOI: https://doi.org/10.5038/data_geo.00001

Esmaeili, S., Kruse, S., Garry, W. B., Whelley, P., Young, K., Jazayeri, S., \& Bell, E. (2018a, December). Migration of ground penetrating radar (GPR) data to image the floor of lava tubes; TubeX project. In AGU Fall Meeting Abstracts.

Esmaeili, S., Kruse, S., Garry, W. B., Whelley, P., Young, K., Jazayeri, S., \& Bell, E. (2018b, December). GPR imaging of lava tubes with the TubeX project. In AGU Fall Meeting Abstracts. essoar.org/doi/10.1002/essoar.10500862.1

Esmaeili, S., Kruse, S., Garry, W. B., Whelley, P., Young, K., Jazayeri, S., et al. (2017, December). Resolution of lava tubes with ground penetrating radar: Preliminary results from the TubeX project. In AGU Fall Meeting Abstracts.

Garry, W. B., Hughes, S.S., Kobs Nawotniak, S. E., Heldmann, J. L., Lim, D. S. S., and the SSERVI FINESSE team. (2016). Exploring lava tubes with LiDAR at Craters of the Moon, Idaho. NASA SSERVI Exploration Science Forum. July 20-22, 2016. Abstract NESF2016-053.

Garry, W. B., Hughes, S. S., Kobs Nawotniak, S. E., Whelley, P. L., Lim, D. S. S., \& Heldmann, J. L. (2017). Planetary exploration of lava tubes with Lidar at Craters of the Moon, Idaho, Lunar and Planetary Science XLVIII, Abs. 1207.

Garry, W. B., Whelley, P., Rowland, S. K., Hughes, S. S., Shiro, B., Kobs Nawotniak, S. E., \& Bleacher, J. E. (2016). Exploring lava tubes with LiDAR in Idaho and Hawai'i. Geological Society of America Abstracts with Programs. v. 48, n. 7, abstract 56-13, doi: https://doi.org/ 10.1130/abs/2016AM-282438.

Gazdag, J. (1978). Wave equation migration with the phase-shift method. Geophysics, 43(7), 1342-1351.

Giannopoulos, A. (2005). GprMax2D/3D: Electromagnetic simulator for ground probing radar.

Gooding, J. L. (1992). Soil mineralogy and chemistry on Mars: Possible clues from salts and clays in SNC meteorites. Icarus, 99(1), 28-41. Greeley, R. (1971). Geology of selected lava tubes in the Bend area, Oregon (No. 71). Department of Geology and Mineral Industries.

Greeley, R. (1987). The role of lava tubes in Hawaiian volcanoes. U.S. Geological Survey Professional Paper, 1350(2), $1589-1602$.

Greeley, R., \& Hyde, J. H. (1972). Lava tubes of the cave basalt, Mount St. Helens, Washington. Geological Society of America Bulletin, 83(8), 2397-2418.

Grimes, K. G. (2002). Small Subcrustal Lava Caves: Examples from Victoria, Australia.

Grimm, R., Heggy, E., Clifford, S., \& Dinwiddie, C. (2005, February). Scattering limits to depth of radar investigation: Lessons from the Bishop Tuff. In Workshop on Radar Investigations of Planetary and Terrestrial Environments.

Hamran, S. E., Berger, T., Brovoll, S., Damsgård, L., Helleren, Ø., Øyan, M. J., et al. (2015, July). RIMFAX: A GPR for the Mars 2020 rover mission. In 2015 8th International Workshop on Advanced Ground Penetrating Radar (IWAGPR)(pp. 1-4). IEEE.

Haruyama, J., Hioki, K., Shirao, M., Morota, T., Hiesinger, H., van der Bogert, C. H., et al. (2009). Possible lunar lava tube skylight observed by SELENE cameras. Geophysical Research Letters, 36, L21206. https://doi.org/10.1029/2009GL040635 
Haruyama, J., Kaku, T., Shinoda, R., Miyake, W., Kumamoto, A., Ishiyama, K., et al. (2017, March). Detection of lunar lava tubes by lunar radar sounder onboard SELENE (Kaguya). In Lunar and Planetary Science Conference (Vol. 48).

Heggy, E., Clifford, S. M., Grimm, R. E., Dinwiddie, C. L., Wyrick, D. Y., \& Hill, B. E. (2006). Ground-penetrating radar sounding in mafic lava flows: Assessing attenuation and scattering losses in Mars-analog volcanic terrains. Journal of Geophysical Research, 111 , E06S04. https://doi.org/10.1029/2005JE002589

Hon, K., Kauahikaua, J. I. M., Denlinger, R., \& Mackay, K. (1994). Emplacement and inflation of pahoehoe sheet flows: Observations and measurements of active lava flows on Kilauea Volcano, Hawaii. Geological Society of America Bulletin, 106(3), 351-370.

Horz, F. (1985). Lava tubes-potential shelters for habitats. In Lunar bases and space activities of the 21st century (pp. 405-412).

Hurwitz, D. M., Head, J. W., Wilson, L., \& Hiesinger, H. (2012). Origin of lunar sinuous rilles: Modeling effects of gravity, surface slope, and lava composition on erosion rates during the formation of Rima Prinz. Journal of Geophysical Research, 117, E00H14. https://doi.org/ 10.1029/2011JE004000

Jazayeri, S., Kazemi, N., \& Kruse, S. (2019). Sparse blind deconvolution of ground penetrating radar data. IEEE Transactions on Geoscience and Remote Sensing, 57(6), 3703-3712.

Jazayeri, S., Klotzsche, A., \& Kruse, S. (2018). Improving estimates of buried pipe diameter and infilling material from ground-penetrating radar profiles with full-waveform inversion. Geophysics, 83(4), H27-H41.

Jol, H. M. (Ed) (2008). Ground penetrating radar theory and applications. Burlington, MA: Elsevier.

Kaku, T., Haruyama, J., Miyake, W., Kumamoto, A., Ishiyama, K., Nishibori, T., et al. (2017). Detection of intact lava tubes at Marius Hills on the Moon by SELENE (Kaguya) lunar radar sounder. Geophysical Research Letters, 44, 10,155-10,161. https://doi.org/10.1002/ 2017GL074998

Kauahikaua, J., Cashman, K. V., Mattox, T. N., Heliker, C. C., Hon, K. A., Mangan, M. T., \& Thornber, C. R. (1998). Observations on basaltic lava streams in tubes from Kilauea Volcano, island of Hawai'i. Journal of Geophysical Research, 103(B11), 27,303-27,323.

Keszthelyi, L. (1995). A preliminary thermal budget for lava tubes on the Earth and planets. Journal of Geophysical Research, 100(B10), 20,411-20,420.

Khan, S. D., Heggy, E., \& Fernandez, J. (2007). Mapping exposed and buried lava flows using synthetic aperture and ground-penetrating radar in Craters of the Moon lava field. Geophysics, 72(6), B161-B174.

Larson, C. V., \& Larson, J. (1990). Lava Beds Caves. ABC Pub.

Lehmann, F., \& Green, A. G. (2000). Topographic migration of georadar data: Implications for acquisition and processing Topographic Migration of Georadar Data. Geophysics, 65(3), 836-848.

Meglich, T. M., Williams, M. C., Hodges, S. M., \& DeMarco, M. J. (2003). Subsurface geophysical imaging of lava tubes, Lava Beds National Monument. CA, Geophysics.

Milsom, J., \& Eriksen, A. (2013). Field geophysics.

Miyamoto, H., Haruyama, J., Rokugawa, S., Onishi, K., \& Palmero, A. (2002). Ground penetrating radar to detect lava tubes: Preliminary results of a GPR application to Fuji volcano. Japan: Lunar and Planetary Science XXXIII, abstract, (1482).

Miyamoto, H., Haruyama, J.'., Kobayashi, T., Suzuki, K., Okada, T., Nishibori, T., et al. (2005). Mapping the structure and depth of lava tubes using ground penetrating radar. Geophysical Research Letters, 32, L21316. https://doi.org/10.1029/2005GL024159

Miyamoto, H., Haruyama, J. I., Rokugawa, S., Onishi, K., Toshioka, T., \& Koshinuma, J. I. (2003). Acquisition of ground penetrating radar data to detect lava tubes: Preliminary results on the Komoriana cave at Fuji volcano in Japan. Bulletin of Engineering Geology and the Environment, 62(4), 281-288.

Neal, A. (2004). Ground-penetrating radar and its use in sedimentology: Principles, problems and progress. Earth-Science Reviews, 66(3-4), 261-330.

Northup, D. E., Melim, L. A., Spilde, M. N., Hathaway, J. J. M., Garcia, M. G., Moya, M., et al. (2011). Lava cave microbial communities within mats and secondary mineral deposits: Implications for life detection on other planets. Astrobiology, 11(7), 601-618. https://doi. $\operatorname{org} / 10.1089 /$ ast.2010.0562

Olhoeft, G. R. (1991). Magnetic and electrical properties of martian particles.

Olhoeft, G. R., Sinex, D. B., Sander, K. A., Lagmanson, M. M., Stillman, D. E., Lewis, S., et al. (2000, April). Hot and cold lava tube characterization with ground penetrating radar. In Eighth International Conference on Ground Penetrating Radar (Vol. 4084, pp. 482-488). International Society for Optics and Photonics.

Ollier, C. D., \& Brown, M. C. (1965). Lava caves of Victoria. Bulletin of Volcanology, 28(1), 215-229.

Peterson, D. W., Holcomb, R. T., Tilling, R. I., \& Christiansen, R. L. (1994). Development of lava tubes in the light of observations at Mauna Ulu, Kilauea Volcano, Hawaii. Bulletin of Volcanology, 56(5), 343-360.

Peterson, D. W., \& Swanson, D. A. (1974). Observed formation of lava tubes. Studies in Speleology, 2(6), $209-222$.

Phillips, R. J., Seu, R., \& Team, S. (2005, February). SHARAD: Radar sounder on the 2005 Mars Reconnaissance Orbiter. In Workshop on Radar Investigations of Planetary and Terrestrial Environments.

Picardi, G., Biccari, D., Seu, R., Marinangeli, L., Johnson, W. T. K., Jordan, R. L., et al. (2004). Performance and surface scattering models for the Mars Advanced Radar for Subsurface and Ionosphere Sounding (MARSIS). Planetary and Space Science, 52(1-3), 149-156.

Ramsey, D. W., Felger, T. J., Ellen, L., Bruggman, P. E., \& Donnelly-Nolan, J. M. (2010). Database forthe geologic map of Medicine Lake Volcano, Northern California. In J. M. Donnelly-Nolan (Ed.). Geologic map ofMedicine Lake volcano. Northern CA: U.S. Geological Survey Scientific Investigations Map 2927.

Ristow, D., \& Rühl, T. (1994). Fourier finite-difference migration. Geophysics, 59(12), 1882-1893.

Robinson, M. S., Ashley, J. W., Boyd, A. K., Wagner, R. V., Speyerer, E. J., Ray Hawke, B., et al. (2012). Confirmation of sublunarean voids and thin layering in mare deposits. Planetary and Space Science, 69(1), 18-27. https://doi.org/10.1016/j.pss.2012.05.008

Rowell, C. R., Pidlisecky, A., Irving, J. D., \& Ferguson, R. J. (2010). Characterization of lava tubes using ground penetrating radar at Craters of the Moon National Monument, USA. Tech. rep. CREWES Research Report, 22, 1-18.

Safaeinili, A., Biccari, D., Bombaci, O., Gurnett, D., Johnson, W. T. K., Jordan, R. L., et al. (2001). Radar sounding of Mars: A focus on MARSIS

Sandmeier, K. J. (1998). ReflexW. Program for the processing of seismic, acoustic or electromagnetic reflection, refraction and transmission data. Karlsruhe, Germany: Sandmeir Software.

Sauro, F., Pozzobon, R., Deberardinis, P., Massironi, M., \& De Waele, J. (2018, March). Morphometry of Terrestrial, Lunar, and Martina Lava Tube Candidates. In Lunar and Planetary Science Conference (Vol. 49).

Seu, R., Biccari, D., Orosei, R., Lorenzoni, L. V., Phillips, R. J., Marinangeli, L., et al. (2004). SHARAD: The MRO 2005 shallow radar. Planetary and Space Science, 52(1-3), 157-166.

Smitha, N., Bharadwaj, D. U., Abilash, S., Sridhara, S. N., \& Singh, V. (2016). Kirchhoff and FK migration to focus ground penetrating radar images. International Journal of Geotechnical Engineering, 7(1), 4. 
Stillman, D., \& Olhoeft, G. (2008). Frequency and temperature dependence in electromagnetic properties of Martian analog minerals. Journal of Geophysical Research, 113, E09005. https://doi.org/10.1029/2007JE002977

Stillman, D. E., \& Olhoeft, G. R. (2005). EM properties of magnetic minerals at RADAR frequencies.

Stockwell, J. W. Jr. (1999). The CWP/SU: Seismic Un*x package. Computers \& Geosciences, 25(4), 415-419.

Wagner, R. V., \& Robinson, M. S. (2014). Distribution, formation mechanisms, and significance of lunar pits. Icarus, 237, 52-60.

Waters, A. C., Donnelly-Nolan, J. M., and Rogers, B. W. (1990). Selected caves and lava-tube systems in and near Lava Beds National Monument, California. USGS Bulletin 1675. 102 p.

Whelley, P., Garry, W. B., Young, K., Kruse, S., Esmaeili, S., Bell, E., \& Paylor, R. (2017, December). Visualizing lava flow interiors with LiDAR. In AGU Fall Meeting Abstracts.

Whelley, P. L., Garry, W. B., Hamilton, C. W., \& Bleacher, J. E. (2017). LiDAR-derived surface roughness signatures of basaltic lava flow types at the Muliwai a Pele Lava Channel, Mauna Ulu, Hawai'i. Bulletin of Volcanology, 79(11), 1-13. https://doi.org/10.1007/s00445017-1161-5

Wilson, L., \& Head, J. W. III (1994). Mars: Review and analysis of volcanic eruption theory and relationships to observed landforms. Reviews of Geophysics, 32(3), 221-263.

Xiao, L., Zhu, P., Fang, G., Xiao, Z., Zou, Y., Zhao, J., et al. (2015). A young multilayered terrane of the northern Mare Imbrium revealed by Chang'E-3 mission. Science, 347(6227), 1226-1229. https://doi.org/10.1126/science.1259866

Yilmaz, O. (1987). Seismic data processing: Soc. Expl. Geophys, 252.

Young, K. E., Whelley, P., Kruse, S., Esmaeili, S., Jazayeri, S., Garry, W. B., et al. (2018, December). Developing a strategy for lava tube exploration by deploying field portable instrumentation in an analog environment. In AGU Fall Meeting Abstracts.

Young, K. E., Whelley, P. L., Kruse, S., Esmaeili, S., Jazayeri, S., Bell, E., \& Schmerr, N. (2018, March). Using GPR, LiDAR, magnetometry, and in situ geochemistry to develop a strategy for the exploration and characterization of lava tubes. In Lunar and Planetary Science Conference (Vol. 49)

Zhu, J., \& Lines, L. R. (1998). Comparison of Kirchhoff and reverse-time migration methods with applications to prestack depth imaging of complex structures. Geophysics, 63(4), 1166-1176. 